\title{
Normas de derechos humanos: Colisión y complementariedad
}

\author{
Human rights standards: \\ Collision and complementarity
}

\section{Laura Nahabetián Brunet}

Universidad de la República

Inahabetian@gmail.com

DOI: http://dx.doi.org/10.22235/rd.v0i14.1237

\begin{abstract}
RESUMEN: El artículo refiere al análisis de necesaria realización frente a la existencia de disposiciones normativas que reconociendo derechos fundamentales, pudieren verificarse en situación de complementariedad y eventualmente en aquella de colisión. De esta forma se pretende avanzar sobre la consideración de los diferentes análisis que deben realizarse a partir de la existencia de las siempre presentes, antinomias normativas, considerando con especial énfasis la estructura de las normas continentes de derechos humanos, el significado de su limitación y su contenido esencial. Asimismo, se analizan algunas consideraciones relacionadas con los principios que deben estar presentes en tanto sustento de las decisiones en la materia.
\end{abstract}

Palabras clave: derechos humanos; eficacia; límites; contenido esencial; principios. ABSTRACT: This article is created due to the necessary analysis of law dispositions that recognize fundamental rights and can be verified both in situations of complementarity and collision.

In this scenario, the article intends to advance in the consideration of the different analysis that have to be done due to the constant existence of regulation antinomies, considering a special emphasis in the structure of regulations that refer to human rights, the meaning of their limitation and their essential content.

Furthermore, an analysis of some considerations related to principles that have to appear as sustentation of the decisions related to this matter is presented.

KEYWORDS: human rights; efficacy; limits; essential content; principles. 
SUmARIO: 1. Introducción. a) Respecto de la constitucionalización del Derecho. b) Eficacia normativa de las normas constitucionales. c) Eficacia horizontal de los derechos fundamentales. d) Acerca de las antinomias normativas. e) Colisión o complementariedad. I) Teoría negatoria. II) Teoría de la aceptación. 2. Estructura de las normas de derechos humanos. a) Disposiciones normativas y norma de derecho fundamental. b) Derechos fundamentales como normas de principio. c) Dimensiones subjetiva y objetiva de las normas que garantizan derechos fundamentales. 3. Limitación a los derechos humanos. a) Limitar un derecho fundamental. b) Delimitación de los derechos fundamentales: límites internos. c) Límites de los derechos fundamentales en sentido propio: los límites externos. d) Límite de los límites: Contenido esencial de los derechos humanos. 4. Principio de proporcionalidad. 5. Principio de razonabilidad. Strict scrutiny. Intermediate scrutiny. Rational basis review. 6. Interpretación normativa. La directriz de preferencia de normas. La directriz de preferencia. 7. Ley de ponderación 


\section{INTRODUCCIÓN}

\section{A) RESPECTO DE LA CONSTITUCIONALIZACIÓN DEL DERECHO}

El término constitucionalización no reviste precisamente exactitud. Tal y como se ha indicado por varios autores, implica la designación de una mutación de un estado a otro. Así, se lo designa como un proceso al término del cual el Derecho es "impregnado", "saturado" o "embebido" por la Constitución"1.

Es imposible por tanto, afirmar con rigurosidad en qué consiste con precisión este proceso. Sin embargo, sí es posible establecer que después de él, el derecho es diferente. En ese sentido, la constitucionalización implica una modificación de paradigma en relación con el antiguo Estado Legal de Derecho determinándose que "un ordenamiento jurídico constitucionalizado se caracteriza por una Constitución extremadamente invasora, entrome- tida, capaz de condicionar tanto la legislación como la jurisprudencia y el estilo doctrinal, la acción de los actores políticos, así como las relaciones sociales"2.

Se trata de la Constitución y su poderoso efecto de irradiación, explicado como "el desbordamiento de un derecho constitucional que ahora inunda el conjunto del ordena- miento; ya no se trata sólo de regular las 
Laura Nahabetián Brunet, Normas de derechos humanos: Colisión y complementariedad, 65-110

relaciones entre los poderes del Estado, sino que casi podría decirse que todo conflicto jurídico, desde el horario de las panaderías al etiquetado de chocolate, encuentra alguna respuesta constitucional"3.

1 Comanducci, Paolo, "Formas de neoconstitucionalismo: un análisis metateórico", en AAVVNeoconstitucionalismo (Madrid, Trotta, 2003), 81.

2 Guastini, Riccardo, "La constitucionalización del ordenamiento jurídico: el caso italiano", en $A A V V$ Neoconstitucionalismo (Trotta, Madrid, 2003), 49.

3 Prieto Sanchís, Luis, "Constitucionalismo y garantismo", en AAVV Garantismo, Estudios en homenaje a Ferrajoli

(Trotta, Madrid, 2005), 48. 
La pregunta inmediata es, qué sucede con aquella hasta este momento poderosa ley. Y la respuesta parece despejar casi todas las dudas. Así, Zagrebelsky señala que "la ley, un tiem- po medida exclusiva de todas las cosas en el Derecho, cede así el paso a la Constitución y se convierte ella misma en objeto de medición. Es destronada a favor de una instancia más alta"4.

Tal y como estableciera Prieto Sanchís, la fuerza superior de la Constitución no es sino uno de los motivos del decaimiento de la ley: "el mantenimiento de la secular pugna con la potestad reglamentaria que hoy adquiere tintes más complejos", así como "el abandono de las viejas cualidades de abstracción y generalidad a favor de una progresiva "reglamentariza- ción" de la ley, a veces escandalosamente singular, cuando no dictada en beneficio (o en per- juicio) de una sola persona"5 son algunos de los elementos que explicarían la crisis de la ley.

Se trata sí de un fenómeno en construcción y permanente modificación, por lo que sus manifestaciones son múltiples y variadas, lo que dificulta la efectividad de su análisis. Tal vez a esto se deba, el hecho que una de las formas más recurrentes para intentar una explica- ción sea su concepción en tanto proceso que se ejecuta hacia el interior de cada uno de los diferentes sistemas jurídicos.

La constitucionalización es, un proceso; y en él, los sistemas jurídicos están más o me- nos constitucionalizados, según se adopten ciertas condiciones: Constitución rígida, garantía jurisdiccional de la Constitución, fuerza vinculante de la Constitución, la 'sobre interpreta- ción' de la Constitución, interpretación conforme de las leyes a la Constitución, e influencia de la Constitución sobre las relaciones políticas ${ }^{6}$.

De esta forma se verifica configurado, producto de la profunda 
Laura Nahabetián Brunet, Normas de derechos humanos: Colisión y complementariedad, 65-110

influencia de la Constitución en el resto del ordenamiento jurídico, el éxito del modelo del Estado Constitucional de Derecho y con él uno de sus elementos centrales y por lo mismo más genuino, cual es el discurso de los derechos fundamentales.

Una muy fuerte mezcla teórica se produjo en la segunda mitad del siglo pasado, la que indudablemente sostiene el camino para la valoración del discurso de los derechos, que ha sustituido a la tradicional cultura del legalismo. Desde las posturas de Hart y su corres- pondiente ubicación en situación de preeminencia del juez en aquellos casos difíciles por la estructura abierta de las normas, Dworkin y el blindaje a los derechos fundamentales en tanto cartas de triunfo antepuestas a las concepciones de tipo utilitarista y luego, Alexy y la teoría de los derechos fundamentales en tanto principios y la ponderación como mecanismo de solución de conflictos entre estos derechos, hasta Ferrajoli y el garantismo como fórmula

\footnotetext{
Zagrebelsky, Gustavo, El derecho dúctil. Ley, derechos, justicia (Madrid, Trotta, 2003), 40.

Prieto Sanchís, Luis, Justicia Constitucionaly Derechos Fundamentales (Madrid, Trotta, 2009), 118.

6 Guastini, Riccardo, "La constitucionalización del ordenamiento jurídico: el caso italiano”, 49.
} 
de implementación de los derechos fundamentales, indudablemente implican las bases cons- titutivas, coherentes o no, en torno a las cuales se ha construido este influyente discurso de los derechos fundamentales de fines del siglo XX y principios del XXI.

Este discurso de los derechos fundamentales enseña Alexy, se caracteriza, "por cuatro extremos: primero, los derechos fundamentales regulan con rango máximo y, segundo, con máxima fuerza jurídica, objeto, tercero, de la máxima importancia con, en cuarto lugar, máxima indeterminación'7. Este discurso es conectado con el "garantismo jurídico", que implica la formulación de "las técnicas de garantía idóneas para asegurar el máximo grado de efectividad a los derechos reconocidos constitucionalmente"8.

Sin embargo, el discurso propio del constitucionalismo moderno, ha sido firmemente criticado. Tal vez la crítica principal al triunfalismo del discurso de los derechos proviene de quienes apuntan como Brown que: "si bien los derechos, pueden operar como una indiscu- tible fuerza emancipatoria en un momento de la historia - como el movimiento de los Civil Rights en Estados Unidos -, en otro momento pueden volverse un discurso regulador, un medio para obstruir o cooptar demandas políticas más radicales, o ser simplemente la más hueca de las promesas vacías".

A los efectos de esta ubicación, en tanto centralidad neurálgica del discurso de los derechos fundamentales, para el Estado Constitucional de Derecho será imprescindible una rearticulación de la idea de los derechos subjetivos que necesariamente está unida a la consti- tucionalización. Y esto es así, en mérito a que los derechos fundamentales están estructurados en normas con valor jurídico propio que no necesitan, en consecuencia, desarrollo 
Laura Nahabetián Brunet, Normas de derechos humanos: Colisión y complementariedad, 65-110

infraconsti- tucional o legal - eficacia normativa - y segundo, los derechos fundamentales operan en todas las direcciones, incluso, entre privados - eficacia horizontal de los derechos fundamentales-.

\section{B) EFICACIA NORMATIVA DE LAS NORMAS CONSTITUCIONALES}

Europa durante el siglo XIX verificaba una construcción jurídica donde primaba una "concepción predominantemente formalista y legalista de la Constitución. Las cartas de de- rechos eran meras declaraciones de naturaleza política (y no jurídica) que requerirían, si habían de tener algún poder normativo directo, de desarrolloy configuración legal". Deestaforma, los

7 Alexy, Robert, "Derechos Fundamentales y Estado Constitucional Democrático", en $A A V V$ Neoconstitucionalismo (Madrid, Trotta, 2003), 32.

$8 \quad$ Ferrajoli, Luigi, "Juspositivismo crítico y democracia constitucional”, en Isonomía $\mathrm{N}^{\circ} 16$ (México, ITAM, 2002), 16.

9 Brown, Wendy, "Lo que se pierden con los derechos", en AAVV La crítica de los derechos (Bogotá, Siglo del Hombre Editores, 2003), 83. 
derechos fundamentales "calificaban, no como reglas, sino como principios" y "la aceptación de que los derechos eran principios (contenidos en meras "declaraciones") implicaba que no tenían la fuerza normativa directa para ser judicialmente reclamados. Los verdaderos derechos eran tan sólo posiciones directas y concretamente definidas en la ley sustantiva y procesal; los derechos constitucionales en cambio estaban lejos de definir directa y concretamente en qué ocasiones eran violados, en qué ocasiones se imponía su protección o qué remedios se impo- nían para su protección"10.

Sin embargo, avanzando en el tiempo, comienza a imponerse, a partir de los desa- rrollos del constitucionalismo de posguerra, la consideración que la totalidad de las normas constitucionales tienen plena eficacia vinculante, incluidas fundamentalmente aquellas que consagran o reconocen derechos fundamentales de las personas por lo que son susceptibles de producir efectos jurídicos sin necesidad de desarrollo infraconstitucional y fundamental- mente, sin que sea necesario avanzar en desarrollos de índole legislativo.

La Constitución "no es un catecismo político o una guía moral dirigida al legislador virtuoso, sino, una norma como cualquiera otra que incorpora la pretensión de que la rea- lidad se ajuste a lo que ella prescribe"11. Esto remite directamente al significado de la efica- cia normativa de la Constitución. Así, se reivindicará desde principios de la década de los ochenta a partir de García de Enterría fundamentalmente, que las disposiciones normativas constitucionales tienen efecto normativo ${ }^{12}$, esto es, dejan de considerarse normas "con un valor meramente programático o como un conjunto de recomendaciones $\mathrm{u}$ orientaciones dirigidas al legislador, para consolidar su valor normativo y operar como auténtica norma ju- rídica con eficacia directa e inmediata"13. Los textos constitucionales determinarán en forma expresa esta eficacia normativa 
Laura Nahabetián Brunet, Normas de derechos humanos: Colisión y complementariedad, 65-110

de los derechos fundamentales. De ahí será que surja la afir- mación que señala que, "es indiscutible que los derechos fundamentales son más que mera lírica constitucional"14. De esta forma, la "consecuencia más básica consiste en concebir a los derechos como normas supremas, efectivas y directamente vinculantes, que pueden y deben ser observadas en toda operación de interpretación y aplicación del derecho"15.

10 López Medina, Diego, Teoría impura del derecho (Bogotá, Legis, 2004), 446.

11 Prieto Sanchís, Luis, Justicia constitucional y derechos fundamentales (Madrid, Trotta, 2009), 116.

12 García Enterría, Eduardo, "La Constitución como norma jurídica”, en AAVV La Constitución española de 1978. Estudio sistemático (Madrid, Civitas, 1981), 97-160 y Rubio Llorente, Francisco, "La Constitución como fuente de Derecho", en AAVV Constitución española y fuentes del Derecho, Vol. I, (Madrid, Instituto de Estudios Fiscales, 1979), 53-74.

${ }^{13}$ Sastre, Santiago, "La ciencia jurídica ante el neoconstitucionalismo", en AAVV Neoconstitucionalismo (Madrid, Trotta, 2003), 240.

14 Bernal Pulido, Carlos, "Los derechos fundamentales y la teoría de los principios. ¿Es la teoría de los principios la base adecuada de los derechos fundamentales de la constitución española?", en DOXA, N³0 (2007), 275.

15 Prieto Sanchís, Luis, "El constitucionalismo de los derechos", en AAVV Teoría del neoconstitucionalismo, Carbonell (ed.) (Trotta, Madrid, 2007), 216. 
Ahora bien, esa eficacia directa o normativa de la Constitución no se limita a la regu- lación de las relaciones entre el Estado y los ciudadanos (eficacia vertical), sino que asimis- mo, influye las relaciones entre particulares (eficacia horizontal).

\section{C) EFICACIA HORIZONTAL DE LOS DERECHOS FUNDAMENTALES}

Un elemento central en toda esta evolución constitucional se revela en la denominada "eficacia horizontal de los derechos fundamentales", esto es, "la posibilidad de que los parti- culares esgriman, en contra de otros particulares y en el ámbito de las relaciones privadas, los derechos subjetivos públicos, como por ejemplo, el derecho de propiedad, el derecho a no ser discriminado, la

libertad de emitir opinión, el derecho a la intimidad o el derecho moral del

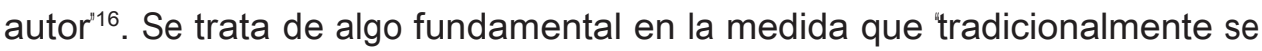
entendía que las normas constitucionales sobre derechos fundamentales se aplicaban únicamente a las relaciones entre los ciudadanos y el Estado; los derechos fundamentales habían aparecido históricamente como derechos de

defensa frente a injerencias de los poderes públicos en la libertad de los particulares, y en consecuencia, no alcanzaban relaciones entre particulares"17.

Se trataba de una concepción unidireccional de los derechos fundamentales desarroIlada al amparo de una filosofía de corte netamente liberal, en relación con la que se habían efectuado las conceptualizaciones de estos derechos.

La doctrina mayoritariamente sostendrá la recepción de la eficacia horizontal de los derechos fundamentales entre particulares ${ }^{18}$, lo que tiene su origen en las determinaciones normativas que indican en términos generales 
Laura Nahabetián Brunet, Normas de derechos humanos: Colisión y complementariedad, 65-110

que la Constitución y el ordenamiento jurídi- co se aplican tanto a los ciudadanos cuanto a los poderes públicos.

Este consenso se verifica en la jurisprudencia internacional, tanto que el Tribunal Europeo de Derechos Humanos, en aplicación de la Convención Europea de Derechos Humanos como la Corte Interamericana de Derechos Humanos en aplicación de la Convención Americana sobre Derechos Humanos, han sostenido la doctrina del efecto ho- rizontal de los derechos fundamentales.

La Corte Interamericana ha determinado que:

16 Peña, Carlos, Sistema Jurídico y Derechos Humanos (Universidad Diego Portales, Santiago, 1996), 668.

17 Ferrer i Riba, Josep, Asociaciones, derechos fundamentales y autonomía privada (Civitas, Madrid, 1997), 89.

18 Pérez Luño, Antonio, Los derechos fundamentales (Tecnos, Madrid, 1998), 67; Ballarín Javier, "Derechos fundamentales y relaciones entre particulares. La Drittwirkung en la jurisprudencia del Tribunal Constitucional", en Revista Española de Derecho Constitucional, CEPC N²4, (1988), 283 y sgtes.; Prieto Sanchís, Luis, Estudios sobre Derechos Fundamentales, Editorial Debate, Madrid, 1990, 205 y sgtes. 

De la obligación positiva de asegurar la efectividad de los derechos humanos protegidos, que existe en cabeza de los Estados, se derivan efectos en relación con terceros (erga omnes). Dicha obligación ha sido desarrollada por la doctrina jurídica y, particularmente, por la teoría del dritt- wirkung, según la cual los derechos fundamentales deben ser respetados tanto por los poderes públicos como por los particulares en relación con otros particulares ${ }^{19}$.

La justificación de la recepción, entonces, de la eficacia horizontal entre los parti- culares se centrará, doctrinariamente, en relación con dos visiones, esto es, aquélla que se enmarca en la propia naturaleza de los derechos fundamentales y aquélla que determina la eficacia a partir del particular tipo de relaciones sociales -de poder- existentes entre los privados involucrados.

De esta manera, en el primer caso, la fundamentación de la eficacia horizontal estará determinada en el carácter objetivo de normas supremas de los derechos fundamentales. Se trata de derechos que por decisión constitucional exhiben la máxima jerarquía jurídica y por ende, su fuerza se impone al conjunto societario, independientemente de la situación de hecho en que se encuentran los particulares ínsitos en la relación.

De esta forma, se establece que estos derechos, en tanto, expresión de un orden básico de valores especificados en las disposiciones normativas de índole constitucional -justicia, libertad, igualdad- y que por tanto otorgan la dirección al ordenamiento jurídico, determi- narán por ello también la rama del Derecho Privado habrá de atenerse a dichos valores, que presentan una serie de exigencias objetivas para su logro"20.

Así, "el posible alcance de una norma de derecho fundamental únicamente lo obten- dremos, precisamente, a partir del análisis de la norma 72 Revista de Derecho (UCUDAL). 2da época. Año 10. Nº 14 (dic. 2016). ISBN 1510-3714. ISBN on line 2393-6193 
que lo pretende, no de su contexto". Y considerando que se configurarán en un doble sentido, en tanto derechos subjetivos propia- mente tales, como elementos objetivos y estructurales del ordenamiento jurídico "se irradian al conjunto de relaciones sociales, incluidas las que suceden entre particulares"21. Además, es menester considerar que es obligatorio aplicar los derechos fundamentales en este sentido horizontal, dada la existencia de relaciones sociales que reproducen, el poder que en forma originaria únicamente era ejecutado por el Estado en relación con los ciudadanos. Se afirma en consecuencia que "hay acuerdo en que la eficacia de que se trata debe ser distinta según la posición de poder que las partes de la relación que ocupen en la sociedad: la Drittwirkung

\footnotetext{
${ }^{19}$ Corte Interamericana de Derechos Humanos. Opinión Consultiva OC -18/03 de 17 de setiembre de 2003 párrafo 140.

20 Naranjo de la Cruz, Rafael, Los límites de los derechos fundamentales en las relaciones entre particulares: la buenafe

(Centro de Estudios Políticos y Constitucionales, Madrid, 2000), 200.

21 Mijanjos y González, Javier, Los derechos fundamentales entre particulares (Porrúa, México, 2007), 7.
} 
es un reflejo de la idea misma de la Constitución como limitación del poder público, sólo que referida al abuso de poder privado o las situaciones en las que un particular goza de una posición de poder dominante en un ámbito determinado de relaciones"22.

Entonces bien, cualquiera que sea el fundamento para la exigibilidad de los derechos fundamentales entre particulares no se verifican dudas vinculadas con su eficacia, ya que la centralidad de la consideración jurídica se ubica en forma en que los derechos se organizan en forma coherente en el interior de la vinculación entre privados.

Eficacia horizontal: directa o inmediata versus indirecta o mediata

Esta idea alemana, no verifica problemas de reconocimiento, sino de construcción en mérito a que "actualmente se acepta, en general, que las normas iusfundamentales rigen en las relaciones ciudadano/ciudadano y, en ese sentido, tienen un efecto en terceros o un efecto horizontal. Lo que se discute es cómo y en qué medida ejercen esta influencia"23. Así se han desenvuelto dos versiones: eficacia directa o inmediata y eficacia mediata o indirecta. La eficacia directa o inmediata de los derechos fundamentales conduce en forma directa las relaciones entre particulares, determinando su oponibilidad entre las partes sin que sea necesario una intermediación jurídica - sea legal o judicial -que facilite su desenvol- vimiento. Implica 'afirmar la virtualidad directa, sin mediaciones concretizadoras, de los de- rechos fundamentales, en tanto derechos subjetivos reforzados por la garantía constitucional, frente a violaciones procedentes de sujetos privados"24. 
En el caso de la eficacia mediata los derechos fundamentales sujetan sólo y directa- mente a las autoridades y poderes públicos, los cuales tendrán la obligación de dar aplicación a las relaciones entre particulares, mediatizados y traducidos en normatividad que los des- envuelvan o en interpretaciones de índole jurisdiccional que los señalen y determinen. En esta concepción desarrollada por el Tribunal Constitucional Federal alemán- los derechos fundamentales funcionan en tanto sistema objetivo de principios y valores que

deben apli- carse por los organismos públicos, que intermedian entre esos derechos y los particulares. La mediación se efectúa por el legislador mediante el dictado de las leyes que los desenvuelven o por los jueces mediante fallos que interpretan la normativa legal vigente en considera- ción de derechos fundamentales, lo que indudablemente configura una interpretación con-

${ }^{22}$ Ferrer i Riba, Josep, Asociaciones, derechos fundamentales y autonomía privada, 99.

${ }^{23}$ Alexy, Robert, Teoría de los derechos fundamentales (Centro de Estudios Políticos y Constitucionales, Madrid, 2007), 510.

${ }^{24}$ Bilbao Ubillos, Juan, La eficacia de los derechos fundamentales entre particulares (Centro de Estudios Constitucionales, Madrid, 1997), 238. 
forme con la Constitución. Estos derechos obligan a los particulares sólo indirectamente, como decisiones valorativas objetivas que se proyectan sobre el conjunto del ordenamiento y, en esa medida, vinculan al legislador y al juez: no son los actos de los sujetos privados, si no las normas de Derecho privado las que están directamente vinculadas a los derechos fundamentales"25. De esta forma, los derechos definen un sistema de valores incorporados a la Constitución, que, en cuanto dotado de un efecto irradiación, debe influir en la interpre- tación del ordenamiento en su conjunto y vincular a todos los poderes del Estado"26.

El debate ha sido extensísimo ${ }^{27}$. Por un lado, quienes se pronuncian a favor de la eficacia indirecta o mediata, destacan su mejor adecuación para con la autonomía de la vo- luntad, dado que no se aplican de golpe los derechos fundamentales al interior del derecho privado.

Por otro lado, los defensores de la eficacia directa sostienen que las relaciones entre privados se verifican regidas por los derechos fundamentales y ésta es la única forma de ver- daderamente otorgar reconocimiento a la jerarquía superior de estos derechos, siendo que su vigor no puede quedar supeditado a la voluntad del legislador o del juez.

La tesis de la eficacia mediata es criticada por artificial, dado que se pretende atribuir las vulneraciones a los derechos fundamentales al legislador o al juez según corresponda, por un teórico error en la protección de estos derechos, ocultando de esa forma, que la vulnera- ción tiene como agente inmediato a un sujeto particular.

No parece haber, aún, una tesis definitivamente consensuada. En la doctrina general aparentemente predomina la tesis de la eficacia inmediata y aún cuando nada es determinan- te, su alcance es cada vez mayor. 


\section{D) ACERCA DE LAS ANTINOMIAS NORMATIVAS}

Una antinomia normativa, esto es, la colisión o contradicción entre normas jurídicas, se verifica cuando en un mismo sistema jurídico "se imputan consecuencias incompatibles a

25 Venegas, María, Derechos fundamentales y derecho privado (Marcial Pons, Madrid, 2004), 115.

${ }^{26}$ Valdés Dal-Ré, Fernando, "Los derechos fundamentales de la persona del trabajador", Informe Congreso Mundial de Derechos del Trabajo, Montevideo, 2003, 72.

${ }_{27}$ Bilbao Ubillos, Juan, La eficacia de los derechos fundamentales entre particulares, 302 y sgtes., Mijanjos y González, Javier, Los derechos fundamentales en las relaciones entre particulares, 11 y sgtes., Arango, Rodolfo, El concepto de derechos sociales fundamentales (Legis, Bogotá, 2005), 99-107, Estrada, Alexei, "Los Tribunales Constitucionales y la eficacia entre particulares de los derechos fundamentales", en AAVV Teoría del neoconstitucionalismo (Trotta, Madrid, 2007), 133-135. 
las mismas condiciones fácticas..."28, es decir, cuando un mismo presupuesto de hecho tiene orientaciones que no son compatibles y por tanto no pueden lograrse en forma simultánea ${ }^{29}$. Prieto Sanchís, ha indicado que el problema se suscita porque los destinatarios de las normas jurídicas incompatibles están imposibilitados de dar cumplimiento al mismo tiem- po a las correspondientes determinaciones, ya que no es viable. De esta forma, en caso de cumplirse la obligación establecida por una norma, se vulneraría la prohibición indicada en la norma contrapuesta; o, si se procediera al ejercicio de un derecho consagrado en otra dis- posición normativa, se incurriría en un ilícito tipificado por la norma que le es antinómica.

Existen diferentes clasificaciones en relación con las antinomias normativas siendo pertinente tener en cuenta aquéllas consideradas en abstracto y aquellas en concreto ${ }^{30}$ :

Antinomias en abstracto, internas, o propias del discurso de validez, son aquéllas que se verifican en relación con las normas cuyos presupuestos de hecho son conceptualmente contrapuestos, generando así una imposibilidad de compatibilidad en caso de verificarse concurrencia. Esta colisión es la que se sucede por ejemplo frente a la existencia de una norma que prohíba las penas crueles y otra que autorice la tortura en comunidades que tradicionalmente acostumbran a ese tipo de "justicia".

En estos conflictos de tipo antinómico, en abstracto puede determinarse en forma anticipada que una de las leyes contradictorias, o bien será inválida, o constituirá una regla general que debe ceder siempre cuando se concretan circunstancias excepcionales.

Esta antinomia se verifica frecuentemente en las normas jurídicas cuya categorización es de reglas, ya que la configuración cerrada y completa de los 
supuestos de hecho que las componen, permite anticipar los casos de confrontación.

Antinomias en concreto, denominadas también como externas, o propias del dis- curso de aplicación, son las que no sugieren en su consideración abstracta incompatibilidad de tipo alguno, por lo que tampoco facilitan el conocimiento previo de los presupuestos de aplicación. Esto imposibilita detectar reglas seguras para solucionar la antinomia. Ambas normas son válidas y, en principio en la consideración del ordenamiento jurídico coherentes, pero eventualmente pueden verificar conflictividad “(...) ni es posible determinar exhaus- tivamente los supuestos de colisión, ni tampoco establecer criterios firmes para otorgar el triunfo a una u otra"31.

28 Prieto Sanchís, Luis, Justicia Constitucional y Derechos Fundamentales (Trotta, Madrid, 2003), 175.

29 Prieto Sanchís, Luis, Justicia Constitucional y Derechos Fundamentales, 175.

${ }^{30}$ Comanducci, Paolo, "Problemas de compatibilidad entre derechos fundamentales", en Garantismo. Estudios sobre el pensamiento jurídico de Luigi Ferrajoli (Trotta - Instituto de Investigaciones Jurídicas, UAM, Madrid, 2005), 108 y sgtes.

${ }^{31}$ Prieto Sanchís, Luis, Apuntes de teoría del Derecho (Trotta, Madrid, 20059, 144. 
Únicamente cuando en una causa particular se verifique la concurrencia de ambas normas, recién ahí será posible advertir la existencia de contradicción y, por lo tanto, la imprescindible justificación razonable y proporcional, que no siempre será igual en todos los casos.

Estas antinomias, son propias de las normas jurídicas que pertenecen a la categoría de principios, en razón de la ausencia de presupuesto de hecho o de su configuración frag- mentaria, y especialmente de los derechos fundamentales consagrados en la Constitución.

Imprescindible es que ésta sea resuelta a los efectos de mantener la imprescindible co- herencia del ordenamiento jurídico. Sin embargo, en mérito a que "el Derecho es un sistema dinámico resulta perfectamente posible que existan contradicciones normativas; pero como, al mismo tiempo, el Derecho es también un sistema estático, de modo que el contenido de sus normas no puede entrar en contradicción con otras superiores, y singularmente con la Constitución, resulta que la coherencia se convierte en un postulado esencial del sistema'32. Las antinomias en abstracto o internas en general se resuelven por parte de los ope- radores jurídicos a través de los tradicionales criterios para solucionar las contradicciones normativas ${ }^{33}$. Ahora bien, los criterios jerárquico y cronológico no tienen utilidad de tipo alguno cuando la colisión se verifica entre normas cuyo origen es un documento legislativo, dado que aquellas tendrán la misma jerarquía y temporalidad en el ordenamiento.

Frente a esta situación el criterio de especialidad aparece como el de adecuada consideración si de los presupuestos de hecho normativos es posible inferir una relación de generalidad y excepcionalidad entre las disposiciones en choque.

Este tipo de antinomia normativa en abstracto que apela finalmente al 
Laura Nahabetián Brunet, Normas de derechos humanos: Colisión y complementariedad, 65-110

criterio de especialidad, no necesariamente está ausente en la normativa constitucional relativa a los derechos fundamentales.

Las antinomias en concreto o externas, por su parte, no son solubles mediante la utilización de los criterios tradicionales. Este tipo de antinomias se verifica con particulari- dades frente a la concurrencia de principios ${ }^{34}$, normas jurídicas cuya pertenencia inmediata es el texto de la Constitución, de donde se extraen, independientemente de la existencia de principios fuera de la misma.

32 Prieto Sanchís, Luis, Apuntes de teoría del Derecho, 132.

33 Zavala Egas, Jorge, Derecho Constitucional, Tomo I 8Edino, Guayaquil, 1999), 183 y 184.

34 Zagrebelsky, Gustavo, El Derecho Dúctil. Ley, derechos, justicia, 110. 
Existen también principios infra constitucionales mas hay que considerar que detrás de cada precepto legal siempre (o casi siempre) es posible encontrar un principio o norma constitucional que lo respalda, y también otro que lo contradice"35.

Admitido que sea que en general son los principios constitucionales los que deter- minan este tipo de antinomias, ni el criterio jerárquico ni el cronológico son de utilidad para solucionar el conflicto normativo concreto. Tampoco aparece como eficaz el criterio de especialidad, ya que los principios estrictamente no poseen condición de aplicación e incluso teniéndola, su configuración es tan fragmentada que no es factible la determinación de una regla de excepción con permanencia que se concilie en una relación de especialidad.

En caso que los principios -en tanto enunciados deónticos carentes de condición de aplicación- no describen cuándo y cómo han de ser aplicados, no es posible establecer entre ellos una relación causal de generalidad a especialidad. La pregunta es de qué manera se puede determinar cuál de los principios es general y correlativamente cuál es especial. Para responder esta interrogante Guastini determina que esto se hará reformulando en sede interpretativa uno de los principios y, precisamente, introduciendo en ellos una cláusula de excepción o exclusión”, lo que por otra parte, constituye según Prieto Sanchís, la pondera- ción misma ${ }^{36}$.

Esto sucede con los derechos fundamentales establecidos en la Constitución.

Sin embargo, de acuerdo con la teoría jurídica contemporánea, los principios cons- titucionales pueden ser de tipo directriz, por lo que funcionan como mandatos de optimi- zación, realizándose o concretándose teniendo en 
consideración las posibilidades fácticas y jurídicas existentes ${ }^{37}$. La nota característica es que la estructura normativa de las directrices presenta una configuración abierta tanto de la condición de aplicación como de la consecuencia jurídica, no existiendo por tanto ninguna orientación para decidir por debajo de qué umbral de satisfacción hemos de considerar vulnerados dichos mandatos constitucionales ${ }^{38}$. De esta forma, la concurrencia antinómica de principios constitucionales no encuentra res- puestas en los criterios clásicos ya que el resultado esperado no admite que se elabore una regla de excepcionalidad constante ni una declaración de invalidez de uno de los principios en conflicto. Por lo tanto, es imprescindible utilizar a un criterio metodológico diferente: la ponderación.

35 Prieto Sanchís, Luis, Apuntes de teoría del Derecho, 145.

${ }^{36}$ Prieto Sanchís, Luis, Justicia Constitucional y Derechos Fundamentales, 180.

37 Alexy, Robert, Teoría de los derechos fundamentales, 86.

${ }^{38}$ Prieto Sanchís, Luis, Justicia Constitucional y Derechos Fundamentales, 183. 


\section{E) COLISIÓN O COMPLEMENTARIEDAD}

"Son bien pocos los derechos considerados fundamentales que no se encuentran en concurrencia con otros derechos considerados también como fundamentales y que no im- pongan, por tanto, en ciertas situaciones y respecto a particulares categorías de destinatarios, una elección (...)"39.

A partir de esta manifestación de Bobbio es posible avanzar en la consideración de la existencia o inexistencia de conflictividad entre derechos fundamentales.

La primera determinación a realizar refiere a la consideración de qué es lo que suce- de, siendo la referencia a conflictos, colisiones, choques de derechos o por el contrario, a la complementariedad que entre diferentes derechos existe.

Cada derecho o libertad, posee límites propios que habilitan la diferenciación de otros derechos o libertades por lo que en principio estos conflictos aparecen como inexis- tentes en la medida que se verifique una adecuada delimitación de los derechos, mediante el sentido común, su descripción correcta por parte del legislador.

Aún cuando esto sucediere la eficacia horizontal de los derechos fundamentales con- juntamente con la opción existente de 'atacar' directamente aquellas acciones de las perso- nas que impliquen infracciones a derechos fundamentales. A partir de lo anterior, en caso que éstas sean contra derechos o libertades constitucionalmente consagrados, esta afirmación implicará aceptar colisiones de derechos fundamentales.

Pero, es importante considerar la opinión de quienes han planteado su escepticismo en relación con esta posible colisión de derechos fundamentales. 
En esa línea, el Profesor Luis Cea Egaña ha señalado "planteamos aquí la tesis según la cual debe buscarse la concilia- ción entre derechos asumiendo como regla general que la colisión entre ellos es sólo aparente y resoluble"40.

Por su parte, el Profesor Pablo Ruiz-Tagle establece que "esa anulación o privación de eficacia es precisamente el efecto que se produce con las concepciones que se basan en la intuición y/o que establecen órdenes rígidos o jerarquías que suponen de aplicación total o absoluta para la resolución de todos los conflictos de derechos"41.

39 Bobbio, Norberto, El tiempo de los derechos (Editorial Sistema, Madrid, 1991), 45.

${ }^{40}$ Cea Egaña, Luis, El sistema Constitucional de chile. Síntesis crítica (Facultad de Ciencias Jurídicas y Sociales de la Universidad Austral de Chile, Valdivia, 1999), 171-175.

${ }^{41}$ Ruiz-Tagle, Pablo, "Una dogmática general para los derechos fundamentales en Chile", en Revista de Derechos Público, 63 (Santiago de Chile, 2001), 179 y sgtes. 
No hay acuerdo en relación con la forma de expresar esta posible colisión de derechos sin perjuicio que los diferentes autores aparentemente comparten un mismo criterio en la sustancia.

De esta forma, es posible señalar que - como ha indicado Peces Barba, incluso sin efectuar una referencia directa al conflicto sino refiriéndose a la eventualidad de un choque entre libertad de expresión y derecho a la intimidad o al honor, señalando "conflictos entre derechos que situamos con el límite del derecho ajeno" - se verifica colisión de derechos "cuando el ejercicio de un derecho fundamental lesione, o ponga en peligro de lesión, el derecho de un tercero"42.

Amplificando la noción de conflicto se incluye en su interior no solamente al enfren- tamiento entre derechos fundamentales de dos o más titulares sino también entre el derecho fundamental de un titular y un principio constitucional.

La idea que se ubica por detrás de estos razonamientos remite a la consideración que indica que la colisión de derechos fundamentales se produce cuando el efecto jurídico de la protección iusfundamental alegada por una persona titular del derecho es incompatible con el efecto jurídico que es perseguido por otra persona a partir de su alegación de protección iusfundamental.

Normativamente, estaría implicando un conflicto entre dos o más normas de derecho fundamental que son aplicables a un determinado caso y que conducen a resultados diferen- tes que además son recíprocamente excluyentes. Esto es así, en mérito a que en la colisión las posiciones de los titulares de los derechos fundamentales se verifican enfrentadas de forma tal que el resultado que se pudiere adjudicar a uno de ellos necesariamente 86 Revista de Derecho (UCUDAL). 2da época. Año 10. N 14 (dic. 2016). ISBN 1510-3714. ISBN on line 2393-6193 
implica la negación de la protección que defiende el otro.

Ahora bien, en relación con las posibles colisiones entre derechos fundamentales se verifica la existencia de dos posturas que por otra parte, son antitéticas.

\section{I) TEORÍA NEGATORIA}

La teoría que niega la posibilidad - al menos desde un punto de vista conceptual - de la colisión de derechos fundamentales, parte de la consideración que indica que cada dere- cho fundamental verifica en sí mismo un límite que se ubica en los derechos de las demás personas, motivo por el cual su propio contenido y ámbito de protección por definición está delimitado por los derechos de los demás. De esta forma, si se produjere una colisión ésta

42 Peces Barba, Gregorio, Curso de Derechos Fundamentales (Universidad Carlos III, Madrid, 1999), 594. 
solamente existiría desde un punto de vista conceptual cuando el titular de un derecho fun- damental pretende el amparo de un derecho excediendo los límites que le son inmanentes. Ignacio de Otto y Pardo sostiene,

(...) en realidad, el problema de los límites de los derechos fundamentales no puede plan- tearse en términos de colisión entre derechos o entre derechos y bienes aceptando que éstos estén definidos en términos tales que choquen entre sí, sino como un problema de interpretación de las normas en las que se trata de delimitar las fronteras de los derechos de trazar los límites en los que la propia norma constitucional configura derechos fundamentales ${ }^{43}$.

El modelo teórico de negación de la colisión implica desde un punto de vista prác- tico una metodología para quien debe enfrentarse a demandas de tutela recíprocamente excluyentes. Así, Martínez Pujalte determina que la referencia a conflictos de derechos no es propiamente tal sino que debe entenderse como

“(...) pretensiones contrapuestas de los sujetos que invocan sus derechos proponiendo que el proceder adecuado" para resolver el aparente conflicto no consiste pues en la determinación del derecho prevalente sino en la delimitación adecuada del contenido de los derechos aducidos para así poder concluir cuál entra realmente en juego y cuál no, quien se encuentra realmente bajo la protección del derecho que invoca y quien se ha extralimitado en el ejercicio de su derecho ${ }^{44}$.

\section{II) TEORÍA DE LAACEPTACIÓN}

La tesis que acepta la eventual existencia de colisiones de derechos avanza a partir de la consideración de la producción de una contradicción entre la protección que se otorga a los derechos fundamentales de dos o más 
personas titulares de los mismos de tal manera que uno deberá prevalecer mientras que el otro tendrá que ser desplazado.

Así es que lo importante en esta teoría será la determinación de un criterio que faci- lite la determinación de la prevalencia que pudiere corresponder en consecuencia de unos derechos por sobre los otros derechos. En este sentido es que se verifica la existencia de varias alternativas, las que refieren a la consideración de un orden de prelación o jerarquía con posible determinación en sentido abstracto entre los diferentes derechos, la posibilidad de la

\footnotetext{
${ }^{43}$ De Otto y Pardo, Ignacio, "La regulación del ejercicio de los derechos fundamentales. La garantía de su contenido esencial en el artículo 53.1 de la Constitución", en Lorenzo Martín Retortillo e Ignacio de Otto y Pardo, Derechos Fundamentales y Constitución (Civitas, Madrid, 1988), 135.

${ }^{44}$ Martínez Pujalte, Antonio, La garantía del contenido esencial de los derechos fundamentales (Centro de Estudios Constitucionales, Madrid, 1997), 135.
} 
ponderación de los derechos en el caso concreto, la idea de la armonización o del equilibrio adecuado.

Estas opciones revisten diferentes críticas que fundamentalmente refieren por un lado a que no existen criterios objetivos que establezcan la determinación de una jerarquía entre derechos fundamentales, o que habiliten a establecer una justificación para la ponderación en un determinado caso, o los mecanismos utilizables para lograr un máximo de protección para cada derecho colisionado. Asimismo, en términos generales no hay en los diferentes or- denamientos jurídicos constitucionales mecanismos que permitan una justificación adecua- da que habilite una fundamentación positiva. $\mathrm{Y}$ esto es muy importante, ya que cualquiera sea la forma elegida para la solución del conflicto, ésta debe dar cumplimiento a una función de carácter dogmático y constituirse con elementos del propio ordenamiento constitucional.

\section{ESTRUCTURA DE LAS NORMAS DE DERECHOS HUMANOS}

\section{A) DISPOSICIONES NORMATIVAS Y NORMA DE DERECHO FUNDAMENTAL}

La referencia a enunciado normativo debe entenderse efectuada a una secuencia fini- ta de palabras que expresan una o varias normas jurídicas y que, en el ámbito de los derechos fundamentales, suele adoptar la forma de un mandato, un permiso o una prohibición ${ }^{145}$.

La pretensión es la identificación del enunciado normativo con un 
precepto de una cierta norma jurídica, con la que se pretende aludir a la proposición de deber ser que es el resultado de los enunciados normativos, sin perjuicio que podrían no necesitar un soporte normativo.

Los derechos fundamentales, - desde el punto de vista de la consideración de su es- tructura -, son normas o conjuntos de normas que se pueden deducir de los enunciados nor- mativos que pueden estar contenidos en preceptos de rango constitucional. De esta forma es que se hace referencia a derechos fundamentales simples o complejos.

En el primer caso, debe considerarse por tales, a aquellos derechos cuyo contenido subjetivo se verifica concretado en facultades jurídicas que permiten a su titular la exigencia

${ }^{45}$ Atienza, Manuel y Ruiz Manero, Juan, Las piezas del Derecho. Teoría de los enunciados jurídicos, (Editorial Ariel, Barcelona, 2007), 1. 
de la observancia de los deberes de abstención o de acción recaídos sobre los poderes públicos o los particulares.

En el segundo caso, la característica fundamental es la inclusión de una pluralidad de técnicas de garantía.

Es necesario tener en cuenta los enunciados normativos que reconocen los derechos involucrados, fundamentalmente, será necesario avanzar en una interpretación de forma tal que se aclare tanto el sentido de las expresiones lingüísticas como aquél de la regla concreta que regula el caso específico y cuya investigación, requerirá la consideración de todos sus elementos.

Esta indagación del contenido de la norma puede ser compleja cuando los enuncia- dos normativos son aquéllos propios de los derechos fundamentales, ya que generalmente se verifica una formulación abstracta y abierta, que al decir de Ignacio de Otto, se origina, o bien en la mención genérica de una conducta que en la realidad ha de verificarse siempre como algo concreto, susceptible de una multiplicidad de formulaciones, o bien, de la pres- cindencia de la pluralidad de facultades con que puede alcanzarse la finalidad a que sirve el derecho en tanto instrumento.

Se ha establecido que los enunciados normativos de las normas de derechos funda- mentales son abstractos en tanto no incluyen referencias al modo, tiempo y lugar de ejercicio del derecho, y es calificado como abierto ya que, de principio, cualquier conducta que encaje en el enunciado normativo estará protegida por el derecho fundamental. Estos atributos convierten al derecho fundamental en una garantía de opciones, cuya concreción se verifica garantizada a menos que exista una expresa habilitación constitucional para su privación. 


\section{B) DERECHOS FUNDAMENTALES COMO NORMAS DE PRINCIPIO}

Ronald Dworkin primero y Robert Alexy luego, han desarrollado dogmática y am- pliamente la diferenciación entre principios y reglas.

De esta forma y siguiendo a Alexy, se afirma que un elemento determinante de la diferenciación entre reglas y principios viene dado por el hecho que éstos son normas que mandan que algo sea efectuado en la mayor medida posible, dentro de las posibilidades jurídicas y reales existentes. Esta es la razón por la que se afirma que los principios son man- datos de optimización, cuya característica central se encuentra en el hecho de que pueden ser cumplimentados en diferente grado y que la medida debida de su cumplimiento no depende únicamente de las posibilidades de hecho sino también de aquellas de derecho. En cambio, 
las reglas implican normatividad que sólo podrá ser, o no, cumplida, de forma tal que su validez determina su exigibilidad completa.

Los derechos fundamentales en general han sido enunciados de manera genérica, sin perjuicio que las constituciones han querido otorgarles una protección jurídica preferente en determinados ámbitos sustantivos. De esta forma, el Tribunal Constitucional Español en un caso vinculado con libertad de expresión, por ejemplo, ha indicado que "no cabe duda de que cuando estas libertades operan como instrumento de los derechos de participación polí- tica debe reconocérseles si cabe una mayor amplitud que cuando actúan en otros contextos, ya que el bien jurídico fundamental por ellas tutelado, que es también aquí el de la forma- ción de la opinión pública libre, adquiere un relieve muy particular en esta circunstancia, haciéndoles "especialmente resistente(s), inmune(s) a las restricciones, que es claro que en otro contexto habrían de operar" ${ }^{\prime \prime 6}$.

Por tanto en las constituciones - múltiples - que han acogido un modelo mixto de principios y reglas, en términos generales, sus normas de derechos fundamentales responden al modelo de las normas de principio en la medida que se presentan mayoritariamente como enunciados que no especifican las reglas jurídicas concretas que se corresponden con las conductas protegidas y sus instrumentos de protección. Puede afirmarse que lo que efectúan mayormente es la ordenación a los poderes públicos $y$, particularmente, al legislador para que otorgue protección específica a la libertad determinada en la mayor medida posible, estable- ciendo reglas concretas que precisen la forma, el espacio y el tiempo del régimen jurídico que el derecho fundamental ha determinado para la conducta del sujeto, de los 
poderes públicos y de otros sujetos involucrados.

La configuración de las normas de derechos fundamentales en tanto "normas de prin- cipio" se visualiza especialmente al momento de verificarse una situación de conflicto entre diversas acciones con pretensión de amparo en un derecho fundamental. Es en estas situa- ciones, en las que la garantía del principio de proporcionalidad desdobla toda su eficacia, el carácter del derecho fundamental en tanto norma de principio, ya que la solución a esta conflictividad difícilmente se verifique de forma directa en el enunciado jurídico, sino que será ubicado a partir del proceso de concreción del objeto, contenido y límites del derecho en las específicas circunstancias del caso. Esto es así en mérito a la necesidad de remitirse al principio de proporcionalidad, dada su condición de técnica mediante la cual se concretiza el mandato de optimización que es parte en todo derecho fundamental.

${ }^{46}$ Tribunal Constitucional del Reino de España, Sentencia STC N¹57/1996, de 15 de octubre de 1996 FJ 5 y Sentencia STC N¹36/1999, de 20 de julio de 1999, FJ 15. 


\section{C) DIMENSIONES SUBJETIVA Y OBJETIVA DE LAS NORMAS QUE GARANTIZAN DERECHOS FUNDAMENTALES}

En cada uno de los derechos fundamentales es factible la diferenciación entre una dimensión de carácter objetivo y una dimensión de carácter subjetivo.

El mandato de optimización tiene incidencia directa en el contenido y el objeto de los derechos fundamentales particularmente en relación con el contenido objetivo del derecho fundamental en la medida que el mandato impone, por una parte que todo poder público tiene el deber positivo de proteger los derechos fundamentales que puedan involucrarse en un determinado caso y por otra parte, determina la obligación de abstención en el desarrollo de actos que pudieren resultar contrarios al deber positivo señalado.

Por lo tanto, el resultado de este mandato, estaría implicando que los poderes pú- blicos se instituirían como garantes de los derechos fundamentales en la medida que en el ejercicio de sus potestades se verifiquen implicados derechos fundamentales.

En relación con el objeto del derecho, el mandato de optimización implica que en mérito a la indefinición jurídica del comportamiento constitucionalmente lícito, en princi- pio todas las facultades de actuación que pudieren corresponder dentro del ámbito de rea- lidad determinado en forma abstracta en el precepto que contiene el derecho fundamental, son acreedoras de protección y, por lo mismo, queda imposibilitada la participación del poder público en ese ámbito.

Los derechos fundamentales son componentes estructurales 
centrales, ya que impli- can la expresión jurídica de un sistema de valores que tiene por finalidad informar a todo el entramado de la institucionalidad jurídica y política.

La condición de fundamentales que se atribuye entonces a ciertos derechos no de- viene únicamente de su inmanencia al ser humano, sino también de la trascendencia que el sistema constitucional otorga a las personas y su funcionamiento en el entramado jurídico - institucional.

Entonces bien, la libertad y la igualdad, centrales en lo que hace a la dignidad de la persona y ésta devenida en uno de los fundamentos del ordenamiento político institucional, genera un importante reconocimiento a la doble dimensión individual y colectiva que ésta reviste.

La dimensión individual implica que la persona se considera en tanto sujeto de de- rechos, y la dimensión colectiva, que la dignidad se hace patente en relación con todos los individuos. 
Con la centralidad adquirida por la dignidad de la persona y por tanto, por la libertad e igualdad de todas las personas, los derechos fundamentales se ubican en el centro de toda la normatividad, siendo que se despliegan todos sus efectos tanto frente a los particulares cuanto a los poderes públicos.

Del significado y finalidad de los derechos fundamentales en el marco del ordena- miento constitucional es posible extraer la importancia de la garantía de su vigencia plena que no es factible de ser limitada a la eventualidad del ejercicio de pretensiones por las per- sonas, sino que debe también asumirse por el Estado.

De la obligación de someterse que todos los poderes tienen a la Constitución no se deduce solo la obligación negativa del Estado de evitar la lesión en la esfera individual o institucional protegida por los derechos fundamentales, sino la obligación positiva de con- tribución a su efectividad, junto con los valores que representan, aún frente a la inexistencia de pretensiones de carácter subjetivo por parte de las personas.

\title{
LIMITACIÓN A LOS DERECHOS HUMANOS
}

\author{
A) LIMITAR UN DERECHO FUNDAMENTAL \\ El Tribunal Constitucional Español ha señalado:
}

Como ya ha declarado en anteriores ocasiones este Tribunal, es cierto que los derechos fun- damentales no son absolutos, pero no lo es menos que tampoco puede atribuirse dicho carácter a los límites a que ha de someterse el ejercicio de los mismos. Todas las personas relativas a tales derechos se integran en un único 
Laura Nahabetián Brunet, Normas de derechos humanos: Colisión y complementariedad, 65-110 ordenamiento inspirado por los mismos principios; y tanto los derechos individuales como sus limitaciones, en cuanto éstas derivan del respeto a la Ley y a los derechos de los demás, son igualmente considerados por el art. 10.1 de la Constitución como "fundamento del orden político y de la paz social". Se produce así, en definitiva, un régimen de concurrencia norma- tiva, no de exclusión, de tal modo que tanto las normas que regulan el derecho fundamental como las que establecen límites a su ejercicio vienen a ser igualmente vinculantes y actúan recíprocamen- te. Como resultado de esta interacción, la fuerza expansiva de todo derecho fundamental restringe, por su parte, el alcance de las normas limitadoras que actúan sobre el mismo; de ahí la exigencia de que los límites de los derechos fundamentales hayan de ser interpretados con criterios restrictivos y en el sentido más favorable a la eficacia y a la esencia de tales derechos ${ }^{47}$.

47 Tribunal Constitucional del Reino de España, Sentencia STC N 159/1986, de 12 de diciembre de 1986, FJ 6. 
Otto y Pardo ha establecido que "en el sentido propio del término (un límite a un derecho fundamental), es una reducción impuesta exteriormente al contenido del derecho o libertad objeto de reconocimiento constitucional mediante la exclusión de determinados supuestos fuera del ámbito de protección (del derecho fundamental) en virtud de una ex- presa habilitación constitucional'48. De esta manera, es necesario indicar que la limitación de un derecho fundamental, cualquiera que fuere su naturaleza, implica sin excepciones la negación de la garantía iusfundamental a una conducta que podría ser encuadrara en la finalidad de este derecho.

Ahora bien, los elementos que caracterizan desde un punto de vista técnico a un límite de derecho fundamental, son tres: el carácter externo, la proyección que revista sobre el objeto del derecho fundamental y la necesidad de que la Constitución autorice al poder público la limitación de derechos fundamentales.

Un tema de singular importancia está determinado por quién puede crear o imponer límites a los derechos fundamentales.

Tratándose de límites de carácter interno ${ }^{49}$, de principio no hay reglas determinadas vinculadas con su concreción ya que éstos poseen eficacia directa. Esto genera la paradoja de habilitar que quienes están dotados de la posibilidad de interpretar y aplicar la normativa podrían llegar a delimitar los derechos fundamentales mediante la concreción de sus límites internos.

Diferente es la situación con los límites de carácter propio $^{50}$ en la medida que éstos sí implican un límite - ya no una delimitación - al derecho fundamental que implica una previa y expresa habilitación constitucional que permite al poder público la creación de una disposición normativa de estas características. 
Un límite a un derecho fundamental implica una suerte de habilitación al poder público para disponer del derecho. La limitación a un derecho fundamental determina que una norma infraconstitucional pueda disponer de la vigencia de la norma iusfundamental ya que podrá decidir si reduce el ámbito normativo de este derecho fundamental, lo que únicamente podrá suceder cuando en forma expresa la Constitución así lo autorice, en mé- rito a que por esta autorización se permite a un poder público la decisión de en qué casos se aplica una disposición normativa constitucional que tiene por finalidad el amparo de ciertas expectativas frente a la imposición unilateral de deberes jurídicos por los órganos del Estado.

${ }^{48}$ De Otto y Pardo, Ignacio, "La regulación del ejercicio de los derechos y libertades. La garantía de su contenido esencial en el art.53.1 de la Constitución", en Derechos fundamentales y Constitución (Retortillo/Otto, Civitas, Madrid, 1988), 35.

${ }_{49}$ Límite interno: criterio de delimitación del objeto del derecho fundamental en cuestión.

50 Límite externo: aquél creado por el poder público habilitado a tal fin por la Constitución. 

Precisamente por esto y a los efectos que esta autorización no implique que el derecho fundamental pierda su condición de tal al resultar disponible, estas autorizaciones guardan relación con un canon constitucional. Este deriva de la indisponibilidad de los derechos que determina la exigencia a toda disposición normativa que especifique limitaciones a los dere- chos fundamentales y, a todo acto de concreción y aplicación de ese límite el cumplimiento de ciertas características que no son unívocas sino que varían en un caso u otro.

Múltiples y variadas son las exigencias que las Constituciones imponen a la creación de límites. Éstos fundamentalmente refieren a la obligación de que estén contenidas en una disposición normativa de rango legal que a su vez deberá establecer en forma precisa, cierta, expresa y previsible la limitación de que se trate y además no podrá generarse la restricción del derecho fundamental de forma tal que pueda violentar su contenido esencial.

Adicionalmente, la disposición normativa con carácter de disposición normativa de restricción de derechos fundamentales deberá respetar las exigencias relativas a su contenido con la finalidad de evitar que ésta incurra en arbitrariedad o lesione el principio de seguridad jurídica del que deriva la necesidad de que la fijación del límite se haga de forma expresa y cierta.

Los actos aplicativos siempre requieren de una expresa y precisa habilitación legal y, además, debe tratarse de un acto con una motivación especial y sometido al principio de proporcionalidad. Al decir del Tribunal Constitucional Español, "cualquier restricción en el ejercicio de un derecho fundamental necesita encontrar una causa específica prevista por la ley y que el hecho o la razón que la justifique debe explicitarse para hacer cognoscibles los motivos que la legitiman'51. 
El acto de restricción del derecho debe señalar - en primer lugar -, la fundamentación, es decir, su habilitación legal deberá ser previa y el bien constitucional que pretende amparar dentro únicamente, de los señalados por la ley habilitante.

En segundo lugar, las motivaciones por las que se considera que el comportamiento individual o colectivo corresponde a quienes se les aplica la restricción legal del derecho fundamental.

En tercer lugar, debe exteriorizarse el juicio de proporcionalidad con el que los ma- gistrados y en caso de corresponder, la administración pública realizan, de ser ese el caso, el debido juicio de optimización de la libertad impuesto por el derecho fundamental en su condición de norma de principio.

51 Tribunal Constitucional del Reino de España, Sentencia STC N 177/1998, de 10 de octubre de 1998, FJ 3. 


\section{B) DELIMITACIÓN DE LOS DERECHOS FUNDAMENTALES: LÍMITES INTERNOS}

De acuerdo con lo señalado, es factible afirmar que existen derechos fundamentales que no son limitables dado que la Constitución no ha previsto límites externos, por lo tanto, no es posible que un poder público les pueda determinar límites.

Pero, en la medida que ningún derecho es ilimitado, porque de alguna forma, to- dos son pasibles a límites inmanentes cuyo origen está en su coexistencia con otras normas constitucionales, es interesante tener presente algunos señalamientos que indicaban que no hay derechos fundamentales. En este sentido, es interesante la consideración que hiciera el Tribunal Constitucional Español, al señalar:

En efecto, no existen derechos ilimitados. Todo derecho tiene sus límites que, como señalaba este Tribunal en Sentencia de 8 de abril de 1981 en relación a los derechos funda- mentales, establece la Constitución por sí misma en algunas ocasiones, mientras en otras el límite deriva de una manera mediata o indirecta de tal norma, en cuanto ha de justificarse por la necesidad de proteger o preservar no sólo otros derechos constitucionales, sino tam- bién otros bienes constitucionalmente protegidos ${ }^{52}$.

Los derechos fundamentales se encuentran contenidos en disposiciones normativas constitucionales que en mérito al principio de unidad constitucional, comparte su existencia con otras de idéntico rango, motivo por el cual es necesario efectuar ajustes al contenido de ellos de manera tal que ninguna se verifique ni preferida ni soslayada por otra. De aquí que se señalara que tanto la igualdad de rango jurídico cuanto el principio de unidad son deter- minantes 
Laura Nahabetián Brunet, Normas de derechos humanos: Colisión y complementariedad, 65-110

de la imposibilidad de contradicción entre estas normas, lo que a su vez trae como consecuencia que el ámbito de aplicación de un derecho fundamental de manera alguna puede extenderse al punto de impedir la aplicación de otras normas de igual rango también de aplicación al caso concreto. De ahí se derivan sus primeros y principales límites.

\section{C) LÍMITES DE LOS DERECHOS FUNDAMENTALES EN SENTIDO PROPIO: LOS LÍMITES EXTERNOS}

Esta limitación en sentido propio tiene un carácter externo, contingente y constitu- tivo. La característica central y definitoria remite a que son restricciones para cuya determi- nación la Constitución habilita a un Poder público, generalmente el legislador. De ahí que

52 Tribunal Constitucional del Reino de España, Sentencia STC N² 2/1982, de 29 de enero de 1982, FJ 5. 
sean límites externos, ya que no devienen de la coexistencia entre derechos fundamentales ni son determinados en forma expresa por la propia Constitución. Esta otorga esa potestad a un poder constituido.

Los límites externos son contingentes, y, por otra parte, su creación es constitutiva. Sin embargo, es menester considerar que el Poder público constituye el límite de por sí, no sólo se limita a su concreción. La proyección del límite externo sobre el objeto del derecho fundamental es asimismo una cuestión importante; la potencialidad de fijación del límite no concretada, determina que éste no exista por lo que la expectativa de conducta eventualmen- te afectada por ese límite goza de la protección del derecho fundamental. Por otra parte esto debe asociarse con el principio de reserva de ley, en la medida que en general estas posibilida- des de fijación de límites externos por el constituyente se pueden realizar únicamente dentro de determinadas pautas que la propia norma constitucional establece, ya que es precisamente ésta la que establecerá un criterio de carácter objetivo para el control de la constitucionalidad de la creación de esta limitación.

Dado que los límites externos son contingentes y constitutivos, el control de su cons- titucionalidad verifica una intensidad y alcance diversos a aquél para el control de la consti- tucionalidad de los límites internos.

Parecería que el legislador tiene mayores posibilidades frente a la fijación de límites de carácter externo que cuando delimita el derecho fundamental efectuando una concreción de sus límites internos. Esto se debe a que cuando interpreta la disposición de derecho fun- damental para determinar sus límites internos concreta la norma fundamental sin tener la chance de avanzar más que hasta donde la propia norma lo establece. Es decir que el legisla- dor en esta efectivización de los límites internos está 
Laura Nahabetián Brunet, Normas de derechos humanos: Colisión y complementariedad, 65-110

directamente en vínculo con las deter- minaciones de tipo abstracto del derecho en cuestión, ya que la Constitución no le permite determinar lo que no ha sido indicado por ella misma.

Sin embargo, cuando el legislador crea límites externos, está utilizando la autorización que la propia Constitución le ha otorgado para restringir sin parámetros preestablecidos. Es decir que la propia habilitación le está atribuyendo al legislador la posibilidad de decidir sobre algo que no está propiamente en la Constitución. Ésta pretende que sea precisamente el legislador el que decida qué bienes o intereses jurídicos estarán presentes en la restricción del derecho fundamental. Esto es sin perjuicio que el legislador seguirá en vínculo con la determinación abstracta que el derecho fundamental otorga a su enunciado constitucional, en mérito al contenido esencial que es invulnerable. De esta manera se comprende que los 
límites externos están asimismo limitados por el contenido esencial del derecho ya que éste implica el núcleo de indisponibilidad de todo derecho fundamental.

Estas limitaciones así indicadas de manera alguna significan que el legislador pueda fundamentar ese límite externo en la genérica garantía de un "interés público" o "general"53. Al momento de la creación de un límite externo, se deberá exigir una no contrariedad con la definición constitucional de tipo abstracto del derecho fundamental y no una compatibi- lidad y conformidad con la norma iusfundamental.

El legislador tiene libertad para la fijación de límites externos a un derecho funda- mental únicamente donde la Constitución en forma expresa lo habilita.

No cabe la posibilidad de fijación de límites implícitos a los derechos fundamentales donde no se verifique la existencia de una cláusula constitucional que expresamente habilite al legislador la determinación de restricciones a los derechos fundamentales, sea que tenga una cláusula de alcance general o que afecte solamente a un derecho fundamental específico

\section{D) LÍMITE DE LOS LÍMITES:}

\section{CONTENIDO ESENCIAL DE LOS DERECHOS HUMANOS}

Loewestein establece:

Entre todos los límites impuestos al poder del Estado se considera que el más eficaz es el reconocimiento jurídico de determinados ámbitos de autodeterminación individual en los que el Leviatán no puede penetrar. ... Estas esferas privadas, dentro de las cuales los destinatarios del poder están libres de la intervención estatal, coinciden con lo que se ha venido a llamar desde hace 
Laura Nahabetián Brunet, Normas de derechos humanos: Colisión y complementariedad, 65-110

trescientos años los derechos del hombre o libertades fundamentales.

[Y avanza más], estas garantías fundamentales son el núcleo inviolable del sistema político de la democracia constitucional, rigiendo como principios superiores del orden jurídico positivo. En su totalidad, estas libertades fundamentales encarna la dignidad del hombre ${ }^{54}$.

Los límites deben tener, a su vez, límites. Esto es, debe existir un núcleo de indispo- nibilidad para el legislador. Por tanto, aparece la búsqueda de un imprescindible equilibrio entre el derecho fundamental y sus límites. Éste es factible de ser alcanzado a través de la utilización de diversas técnicas: la del denominado "contenido esencial" de los derechos fundamentales, la del principio de proporcionalidad, la de la ponderación. "El contenido esencial de los derechos fundamentales es el reducto último que compone la sustancia del

${ }^{53}$ Tribunal Constitucional del Reino de España. Sentencia STC N 37/1989, de 2 de marzo de 1989, FJ 7.

54 Loewestein, Karl, Teoría de la Constitución (Ariel Derecho, Barcelona, 1976), 391. 
derecho, disuelto el cual (aunque sólo sea en alguno de sus elementos) el derecho deja de ser aquello a lo que la Norma Fundamental se refiere" 55 .

De esta forma, el Tribunal Constitucional Español ha indicado que para la especi- ficación del contenido esencial es posible avanzar en dos sentidos diferentes que deberían utilizarse en forma conjunta en tanto se verifican complementarios.

Así, un primer camino estará representado por la relaciones entre el lenguaje y las ideas generalizadas y convicciones generalmente admitidas entre los juristas. A partir de esta determinación, podrá entonces entenderse por contenido esencial "el tipo abstracto del de- recho preexistente conceptualmente al momento legislativo y en ese sentido se puede hablar de una recognoscibilidad de ese tipo abstracto en la regulación concreta". Por lo tanto, cons- tituye contenido esencial de un derecho subjetivo aquellas facultades o posibilidades de ac- tuación necesarias para que el derecho sea recognoscible como perteneciente al tipo descrito y sin los cuales deja de pertenecer a ese tipo y tiene que pasar a quedar comprendido en otro. El segundo camino remite a la noción de intereses jurídicamente protegidos. De esta forma, el contenido esencial de los derechos y libertades, es aquella parte del contenido del derecho que es absolutamente necesaria para que el interés jurídicamente protegible exista, necesaria para dar vida al derecho para que resulte real, concreta y efectivamente protegido. Esto implica, que el contenido esencial es aquella parte del contenido de un derecho sin la cual éste pierde su peculiaridad, o dicho de otro modo, lo que hace que sea recognoscible como derecho perteneciente a un determinado tipo.

La noción de contenido esencial no es inmutable sino un concepto 
Laura Nahabetián Brunet, Normas de derechos humanos: Colisión y complementariedad, 65-110

eminentemente histórico, sujeto a las transformaciones sociales que se vayan produciendo. Y es que ésta parece ser la única vía posible a fin de evitar un anquilosamiento o petrificación de nuestro ordenamiento jurídico ${ }^{56}$. Con la consideración del contenido esencial, se busca asegurar la vinculación positiva del legislador a los derechos fundamentales de manera tal que éste únicamente fije límites en los estrictos términos que establece la Constitución. Si la limitación determinada al derecho fundamental genera afectación en su contenido esencial, lo que está efectuando no es una limitación sino una supresión o privación a su titular. De esta forma y tal y como lo estableciera el Tribunal Constitucional Español ya desde 1981, el contenido esencial implica un límite a los límites de los derechos fundamentales y proponía caminos alternativos para aproximarse a esta idea.

${ }^{55}$ Álvarez Conde, Enrique, El régimen político español (Editorial TECNOS, Segunda Edición, Madrid, 1985), 227 y sgtes.

56 Álvarez Conde, Enrique, El régimen político español, 227 y sgtes.. 

Los dos caminos propuestos para tratar de definir lo que puede entenderse por "con- tenido esencial" de un derecho subjetivo no son alternativos, ni menos todavía antitéticos, sino que, por el contrario, se pueden considerar como complementarios, de modo que, al enfrentarse con la determinación del contenido esencial de cada concreto derecho pueden ser conjuntamente utilizados para contrastar los resultados a los que por una u otra vía pueda llegarse"57.

Sin embargo, con el avance de los estudios en la materia el propio Tribunal ha efec- tuado una modificación en su jurisprudencia que es de destaque. Ha considerado que el contenido esencial de los derechos fundamentales está dado por su titularidad, objeto, conte- nido y límites en la forma abstracta determinada por la norma iusfundamental. Por lo tanto, no habrá un contenido esencial o necesario, y uno no esencial disponible por el legislador, sino que habrá un contenido cuya definición abstracta ha sido dada por la Constitución y un contenido que será concretado por el legislador que tiene una obligación de respeto por el contenido constitucional abstracto del derecho. Esta concreción por parte del legislador es recognoscible en su contenido constitucional siendo acorde con el propósito garantista subyacente.

La sentencia STC $N^{\circ} 292 / 2000^{58}$, reiterando la doctrina de la sentencia STC N¹1/198159, estableció que: "se rebasa o se desconoce el contenido esencial cuando el derecho queda sometido a limitaciones que lo hacen impracticable, lo dificultan más allá de lo razo- nable o lo despojan de la necesaria protección". Y añade ${ }^{60}$ : "De otro lado, ha de señalarse, asi- mismo, que (...) dicha Ley estaría lesionando el contenido esencial del derecho fundamental así restringido, dado que la forma en que se han fijado sus límites 
lo hacen irreconocible e imposibilitan, en la práctica, su ejercicio (STC 11/1981, F.J. 15; 142/1993, de 22 de abril, F.J. 4, y 341/1993, de 18 de noviembre, F.J.7)".

Esta modificación en la justicia constitucional trae por consecuencia que el respeto al contenido esencial deviene en una cláusula de garantía de la indisponibilidad del derecho fundamental y de su disponibilidad por su titular aplicable a toda concreción que el legisla- dor haga de él. Así, el legislador deberá estar sujeto al contenido esencial al momento de la aplicación a las diferentes relaciones jurídicas con los particulares y las de éstos entre sí, así como frente a la fijación de sus límites.

${ }^{57}$ Tribunal Constitucional del Reino de España, Sentencia STC N 11/1981, de 8 de abril de 1981, FJ 8.

${ }_{58}$ Tribunal Constitucional del Reino de España, Sentencia STC N²292/2000, de 30 de 10 noviembre de 2000 , FJ

\footnotetext{
59 Tribunal Constitucional del Reino de España, Sentencia STC N ${ }^{\circ} 11 / 1981$, de 8 de abril de 1981, FJ 8.

15 Tribunal Constitucional del Reino de España, Sentencia STC N²292/2000, de 30 de noviembre de 2000 , FJ
} 
La ya citada STC $N^{\circ} 292 / 2000$, identifica al contenido esencial con la definición abstracta que del derecho hace la Constitución. Es decir que para el Tribunal el contenido esencial del derecho fundamental es el que le otorga la Constitución en una interpretación contextual de su enunciado. De esta forma, el contenido esencial de un derecho remite a su titularidad, es decir quien lo goza, a su objeto, esto es, las expectativas de conducta que se resguardan en la garantía iusfundamental, a su contenido en sentido técnico, esto es el conjunto de facultades y poderes jurídicos que son necesarios para que el objeto del derecho fundamental pueda efectivizarse por el titular, y, los límites internos y aquellos externos que la Constitución prevea.

El Tribunal Constitucional de la República de Chile, se ha manifestado para sostener

que

(...) la esencia del derecho debemos conceptuarla desde el punto de vista del ordenamiento positivo y dentro de este ámbito precisar el alcance de la norma constitucional en los términos más sencillos, para que sea entendido por todo y no sólo por los estudiosos de la ciencia jurídica. Desde esta perspectiva, debemos entender que un derecho es afectado en su "esencia cuando se la prive de aquello que le es consustancial, de manera tal que deja de ser reconocible y que se impide "el libre ejercicio" en aquellos casos en que el legislador lo somete a exigencias que lo hacen irrealizable, lo entraban más allá de lo razonable o lo privan de tutela jurídica $^{61}$.

El Tribunal Constitucional de la República de Colombia, señala que la propia Constitución consagra el núcleo esencial de los derechos, ya que en el mismo sentido de lo que expresa Häberle, indica que, 
(...) se denomina contenido esencial, al ámbito necesario e irreductible de conducta que el derecho protege, con independencia de las modalidades que asuma el derecho o de las formas en que se manifieste. Es el núcleo básico del derecho fundamental, no susceptible de interpretación o de opinión sometida a la dinámica de coyunturas o ideas políticas. ... Según la teoría del núcleo esencial de los derechos, éstos pueden en consecuencia ser canalizados en sus diferentes expresiones, sin ser desconocidos de plano ellos pueden ser moldeados, pero no pueden ser objeto de desnatu- ralización, así como cuando para el ejercicio de un derecho se establezcan requisitos mínimos razo- nables, que apuntan a hacer más viable el derecho mismo y que no desconocen su ámbito esencial, no pueda aducirse que se está violando de pleno tal derecho ${ }^{62}$.

${ }^{61}$ Tribunal Constitucional de la República de Chile, Sentencia N ${ }^{\circ} 43 / 1987$, de 24 de febrero de 1987, Considerandos 20 y 21.

62 Tribunal Constitucional de la República de Colombia, Sentencia C-033/1993, de 8 de febrero de 1993. 
En definitiva, el contenido esencial de un derecho fundamental será el resultado de su delimitación. Ese contenido es el que debe ser respetado por el legislador tanto cuando regula el ejercicio del derecho fundamental como cuando lo desenvuelve.

No es dable olvidar que los límites a un derecho fundamental, forman parte de su contenido esencial, lo que implica que éstos únicamente son los que expresamente están previstos por la Constitución o derivan de la coexistencia del derecho con otras disposiciones normativas que poseen el mismo rango constitucional. Si la pretensión del legislador fuera la determinación de límites no previstos en la Constitución se estaría vulnerando el contenido esencial del derecho fundamental. Es en este sentido en que el contenido esencial opera como un límite a los límites.

De interesante consideración es también la jurisprudencia y doctrina alemanas vin- culadas con la interpretación del art. 19.2 Ley Federal de Bonn vinculadas con qué debe considerarse el contenido esencial como límite a los límites de los derechos fundamentales. La determinación normativa alemana refiere a la regulación del ejercicio de los derechos y no a la determinación de sus límites, tal el caso español, y tiene su fundamento en que los enunciados normativos de varios de los derechos fundamentales contenidos en la norma verifican la existencia de reservas de limitación. Éstas permiten al legislador la fijación de los límites de un derecho fundamental con un importante margen de libertad. Así el citado artículo 19 establece:

1. En tanto en esta LFB un derecho fundamental pueda ser limitado por una ley o con el fundamento de una ley, esa ley debe valer como general y no para un caso concreto. Además, la ley debe nombrar el derecho fundamental con indicación de su precepto". 2. En ningún caso, puede ser 
Doctrinariamente se ha indicado en consecuencia que esta cláusula no debe ser declarativa; parece obvio que toda norma constitucional tiene un contenido esencial que es indisponible al legislador en mérito a su posición de máxima jerarquía. A partir de esta afirmación se desa- rrollaron las teorías relativa y absoluta del contenido esencial de los derechos fundamentales. La teoría relativa establece que la limitación a los límites está dada por la razonabilidad de la restricción impuesta al derecho fundamental. Es decir que la limitación debe ser razonable, y se prohíbe todo límite arbitrario. La consecuencia inmediata de esta teoría es que el contenido esencial del derecho fundamental será el resultado de la consideración razonable y justificada del límite impuesto. Si se verifica la razonabilidad no habrá invasión en el contenido esencial del derecho. 

La teoría absoluta señala que el contenido esencial de un derecho fundamental es efectivamente aquél indisponible al poder limitativo de la ley. El derecho fundamental tiene que ser delimitado conceptualmente en forma previa para identificar este contenido esencial, y determinar cuál no es su contenido esencial, y de esta forma establecer cuál es el ámbito de actuación del legislador para la imposición de límites dentro de la razonabilidad.

En función de lo indicado se considera oportuno, referir en consecuencia a los seña- lamientos que al respecto efectúa el Prof. Risso Ferrand quien determina la siguiente com- partida ordenación:

En primer lugar, los derechos preexistentes, los definidos previamente al ordenamien- to jurídico, los que hacen reconocibles a cada categoría, no pueden ser limitados por ningún acto jurídico, sea éste legal o administrativo. Ni siquiera podría limitarse o privarse de estos derechos mediante una reforma constitucional, ya que el artículo $331^{63}$ no puede autorizar a modificar al que es anterior a la propia Constitución y que la Carta sólo reconoce como existente.

Una ley que limitara de cualquier forma un derecho preexistente sería inconstitucio- nal por afectar un derecho subjetivo de los individuos frente al

Estado legislador; el legislador carece de competencias para la limitación, aun cuando pudiera invocar razones de interés general o nociones similares, que resultarían irrelevantes para limitar un derecho de este tipo.

Pero al mismo tiempo, y en tanto estos derechos preexistentes formulados con el grado máximo de abstracción y generalidad se asocian con la noción de contenido esencial de los derechos humanos, se aprecia que, además de no poder ser limitados, se transforman:

i) en límites claros para la restricción por ley de otros derechos humanos sí 
Laura Nahabetián Brunet, Normas de derechos humanos: Colisión y complementariedad, 65-110

limitables, en la medida que las restricciones que se dispongan a éstos (cumpliendo con la garantía formal de ser establecidas por ley formal - y garantías materiales - estar fundadas en razones de interés general u otros conceptos que maneja nuestra Constitución) no podrán nunca tener una entidad tal que impliquen la desnaturalización del contenido esencial (lo que transfor- maría en inconstitucionales por implicar una limitación indirecta de los preexistentes); y ii) el contenido esencial será una guía básica para el legislador y el administrador en cuanto al punto de partida mínimo de los derechos humanos que deben ser protegidos en un proceso expansivo de protección y reconocimiento.

63 La referencia es a la Constitución de la República Oriental del Uruguay. 


\section{PRINCIPIO DE PROPORCIONALIDAD}

El principio de proporcionalidad remite a "la necesidad de asegurar la supremacía del contenido de las normas relativas a derechos fundamentales frente a la necesaria regulación legislativa" ${ }^{164}$. Implica que toda determinación de autoridad que pudiera restringir un dere- cho fundamental únicamente será factible si es indispensable para el alcance de un objetivo constitucionalmente lícito, de acuerdo con las prohibiciones en el ejercicio del poder que son inherentes al Estado Constitucional de Derecho. Se indica que sirve como criterio de determinación de la legitimidad de la intervención legislativa. Así es posible señalar que este principio cumplirá con una función de tipo argumentativo en la interpretación de los principios fundamentales que pudieren afectarse en una determinada situación, para fijar el significado específico de las previsiones constitucionales a que son tributarios.

De esta forma los tradicionales criterios de interpretación jurídica no son suficientes para determinar las limitaciones a los principios constitucionales en caso de colisiones, en la medida que no han sido formulados para la estructuración abstracta y genérica de las dis- posiciones normativas constitucionales. Estos criterios sí son de recibo y aplicación para el esclarecimiento de algunos temas centrales de inicio como el significado de las disposiciones fundamentales pero no facilitan la determinación precisa de los límites de los principios constitucionales al momento de plantearse un conflicto con características particulares.

Así es que para la determinación de los límites de la relación entre 
Laura Nahabetián Brunet, Normas de derechos humanos: Colisión y complementariedad, 65-110

bienes jurídicos es central la aplicación del principio de proporcionalidad, en mérito a que la precisión de conceptos, ideas y situaciones que puede aportar a los casos concretos, es un procedimiento adecuado para establecer la legitimidad de una medida legislativa que debe promover un bien público. "Con la proporcionalidad es posible establecer resultados o decisiones de ma- nera racional que son bastante aceptables, lo que justifica totalmente el método"65.

La aplicación del principio de proporcionalidad es importante a los efectos de dejar de lado el criterio conflictivista de los principios constitucionales. Éste los considera como "opuestos", y obliga a la imposición de uno de ellos sobre el otro al igual que lo hace con los bienes que tutela. Por el contrario, el principio de proporcionalidad pretende una armonía entre la contraposición.

\footnotetext{
64 Cianciardo, Juan, El principio de razonabilidad. Del debido proceso sustantivo almoderno juicio de proporcionalidad

(Editorial Abaco de Rodolfo Depalma, Buenos Aires, 2004), 31.

${ }^{65}$ Cárdenas Gracia, Jaime, La argumentación como derecho, Instituto de Investigaciones Jurídicas, (UNAM, México, 2005), 150.
} 
El supuesto conflicto no es verificable entre los derechos abstractamente considera- dos sino entre las pretensiones de sus titulares en los casos concretos. Por tanto, la solución vendría a determinarse por la incidencia casuística de determinados criterios y elementos circunstanciales. No es factible, que un bien o derecho exija lesión de otro bien o derecho, sino que debe "conjugarse su finalidad con la perspectiva aportada por la visión coexistencial; los principios constitucionales -como paradigmáticos derechos a la intimidad y a la libertad de expresión- sencillamente no son enemigos naturales"66.

El Tribunal Constitucional Federal alemán se ha pronunciado respecto de este prin- cipio en múltiples oportunidades. Así, ha señalado:

(...) de acuerdo con el principio de proporcionalidad la ley que restrinja un derecho funda- mental debe ser adecuada y necesaria para alcanzar la finalidad deseada. Una ley es adecuada, cuan- do con su ayuda se puede lograr el resultado deseado; es necesaria, cuando el legislador no hubiera podido elegir otro medio, igualmente efectivo, que no restrinja o limite en menor grado el derecho fundamental. Para juzgar la idoneidad y necesidad del medio elegido para alcanzar los objetivos deseados, así como para llevar a cabo en este contexto la evaluación y pronóstico de los peligros que amenazan a los individuos o al interés general, se le ha atribuido al legislador un espacio de decisión, el cual sólo puede ser examinado por el Tribunal Constitucional Federal en forma limitada, depen- diendo de la clase de asunto que esté en discusión y el bien jurídico que esté en juego, de modo tal que éste pueda dictar una sentencia suficientemente segura ${ }^{67}$.

\section{PRINCIPIO DE RAZONABILIDAD}


"La razonabilidad implica que para que una medida sea constitucional es preciso un cierto contenido de justicia. El sentido común y el sentimiento racional de justicia de los individuos permiten apreciar lo que es razonable y lo que es arbitrario, lo que es conforme o no a la justicia, lo que tiene razón suficiente..."68. En principio podría considerarse que ra- zonabilidad y proporcionalidad son determinaciones similares cuya finalidad es parecida en la medida que su pretensión es evitar la arbitrariedad. Sin embargo, estricta y formalmente no son lo mismo.

$66 \quad$ Castillo Córdova, Luis, “¿Existen los llamados conflictos entre derechos fundamentales? Cuestiones Constitucionales2, en Revista mexicana de Derecho Constitucional 12 (enerojunio 2005) UNAM, 128.

${ }^{67}$ Schware, Jürge, CincuentaañosdejurisprudenciadelTribunal Constitucional Federalalemán, (Fundación Konrad Adenauer, Ediciones Jurídicas Gustavo Ibáñez, Bogotá, 2003), 48 y sgtes.

${ }^{68}$ Prats, Eduardo, Derecho Constitucional, Tomo II (Editora Impresos Amigo del Hogar, Santo Domingo, 2012), 2da. Edición, 87. 
Sin embargo, es posible afirmar la existencia de una relación de género a especie entre estos principios. Y esto es así, dado que la idea de razonabilidad implica la proporcionalidad, deviniendo ésta en una consecuencia o incluso una manifestación de aquella, por medio de la que es posible la determinación de si una actuación estatal es o no jurídicamente la más adecuada para perseguir un determinado fin.

De acuerdo con Arancibia ${ }^{69}$, en el juicio de proporcionalidad se pretende la determi- nación del límite constitucionalmente admisible de una intervención estatal en términos de compatibilidad con el respeto a los derechos. Implica la eliminación de la arbitrariedad, y de esta forma, el juicio de proporcionalidad supone el de razonabilidad.

$\mathrm{Sapag}^{70}$ ha indicado que el origen del principio de razonabilidad puede ubicarse en el derecho anglosajón, vinculándose directamente con el denominado due process of Law, cu- yas raíces pueden encontrarse en documentos tales como la Carta Magna de 1215. El origen conceptual, remite a la idea que para que los actos de los poderes públicos verifiquen validez, deben observarse ciertas reglas y procedimientos. Desde sus orígenes el debido proceso ha sido entendido como un principio de carácter procesal; sin embargo, también ha producido una mutación a partir de la interpretación que comenzara a realizarse por parte de la juris- prudencia norteamericana desde finales del siglo XIX.

La V Enmienda de la Constitución de Estados Unidos - ya en 1791 incluye en forma expresa el principio del due process, indicando que nadie estará obligado.... a declarar contra sí mismo en ningún juicio criminal; ni se le privará de la vida, la libertad o la propie- dad sin el debido procedimiento jurídico...." 
En 1868, con la inclusión de la Enmienda XIV, se ratifica la idea del debido proceso, ampliando su ámbito de aplicación "ningún Estado podrá dictar o poner en vigor ley algu- na que menoscabe los derechos e inmunidades de los ciudadanos de los Estados Unidos; y ningún Estado podrá privar a persona alguna de la vida, la libertad, o la hacienda, sin el debido procedimiento jurídico; ni podrá negar a persona alguna bajo su jurisdicción la igual protección de las leyes".

Es entre los años 1886 y 1905, y fundamentalmente a partir de las cláusulas sobre due process, que la Corte Suprema de Estados Unidos de Norteamérica desarrolló una doctrina acerca de la razonabilidad de los actos regulatorios del Estado, estableciendo:

69 Arancibia, Jaime, "fte intensity of judicial review in the commercial context: deference and proportionality", en Efective judicial review. A cornerstone of good governance, forsyth, Christopher; Elliot, Mark; Jhaveri, Swati; Ramsden, Michael, and Scully-Hill, Anne (Editores) (Oxford University Press, 2010), 287-289.

${ }^{70}$ Sapag, Mariano, "El principio de proporcionalidad y de razonabilidad como límite constitucional al poder del Estado: Un estudio comparado", en Dikaion 17 (2008), 163 y 164. 
1. La potestad regulatoria de un servicio público no es ilimitada. Más precisamente, me- diante ella no se puede encubrir una confiscación, a menos que exista una justa compensación o un debido proceso.

2. Al ejercerse la potestad regulatoria del Estado, las normas que sean consecuencia de ellas deben guardar relación sustancial con los objetivos de la regulación.

3. Al ejercerse la potestad regulatoria del Estado, las normas que sean consecuencia de ellas no pueden invadir de manera evidente los derechos y libertades.

4. Las limitaciones y regulaciones deben ser "prudentes".

5.Las leyes regulatorias se presumen inconstitucionales, y el Estado debe probar que existe una relación razonable entre la regulación y el fin perseguido por ésta.

A partir de 1937, la jurisprudencia inicia un camino de distinción en el control de constitucionalidad de la actividad regulatoria del Estado, en mérito al cual, el control se efectúa o analizando que la medida adoptada es razonable desde el punto de vista del debido procedimiento, o a partir del principio de igualdad.

Considerando la redacción de la Enmienda XIV, la Corte analiza el control de una ley regulatoria aplicando el debido proceso sustantivo cuando la regulación remite a un de- recho o libertad que afectará en igualdad de condiciones. Más si ésta genera diferencias entre grupos de personas, la Corte desarrolla el control teniendo en consideración la protección de la igualdad. Lo que se pretende es la comprobación de la existencia o no de una relación razonable entre la regulación legal y el fin con ella perseguido.

A partir de lo señalado, la Corte desarrolló una serie de test a los efectos de otorgar mayor objetividad al control de constitucionalidad cuya base es la 
Enmienda XIV. Los de- nominados scrutiny son tres: strict scrutiny, intermediate scrutiny el rational basis review.

\section{- Strict scrutiny}

Se trata del test más exigente. Este test parte de la presunción de inconstitucionalidad de la regulación de un derecho o libertad que tiene una consideración de preferencia. Se consideran tales, aquellos "derechos que no sólo exigen la más alta protección estatal, sino que también resisten la más mínima de las intromisiones de regulación", tal es el caso de la libertad de información, el derecho a la privacidad, entre otros. El Estado tiene la carga probatoria de la finalidad de la regulación es la promoción de un interés estatal fundamental (compelling state interest) y que es adecuado a su obtención (narrowly tailored).

\section{- Intermediate scrutiny}

Este test verifica aplicación a las regulaciones de los derechos considerados importan- tes. Controla regulaciones estatales al ejercicio de derechos a los efectos de intereses estatales 
legítimos. Así, la Corte tiene una presunción de inconstitucionalidad de la regulación, y el Estado tiene la carga probatoria de la regulación en el sentido de determinar el objetivo gubernamental importante, siendo imprescindible la existencia de una adecuación entre los medios y los fines.

No es imprescindible que la norma haya sido desarrollada a la medida, sin embargo, el tribunal podrá efectuar un juicio de necesidad sobre los medios utilizados considerando otras medidas con menor nivel de discriminación.

La diferencia entre strict scrutiny e intermediate scrutiny es meramente de grado. Podría aplicarse uno u otro dependiendo del carácter de la medida y el derecho regulado. Ahora bien, siempre se trata de derechos constitucionales.

La diferencia entre uno y otro test, remite a que en el caso del escrutinio estricto, la aplicación en general se efectúa en el caso de "libertades preferidas".

\section{- Rational basis review}

Este test es de aplicación en defecto del strict scrutiny y del inmediate scrutiny.

Implica como su nombre lo establece un control de relación razonable.

Contrariamente a los anteriores, la regulación reviste una presunción de constitucio- nalidad, debiendo existir una relación razonable entre ella y el objetivo perseguido. La medi- da considerada constitucional debe mantener una relación de razonabilidad o racionalidad con el fin perseguido, así como legitimidad y adecuación para con los medios. Este test es de aplicación preferente en relación con el debido proceso ${ }^{71}$. Cianciardo ha indicado que "el principio de razonabilidad, viene a dar respuesta en todos los casos a una 
Laura Nahabetián Brunet, Normas de derechos humanos: Colisión y complementariedad, 65-110

preocupación co- mún: la necesidad de asegurar la supremacía del contenido de las normas relativas a derechos fundamentales frente a la necesaria regulación legislativa'72.

La Corte Constitucional de Colombia ha señalado en tanto criterio jurisprudencial a los efectos de la determinación de si una medida limitativa de Derechos Fundamentales es constitucional, racional y proporcional, que el análisis debe efectuarse en torno a los criterios de: análisis de la finalidad buscada por la medida, análisis de los medios empleados y análisis de la relación existente entre el medio empleado y la finalidad perseguida. En este sentido, la Sentencia C 673/2001, de 28 de junio de 2001, señala: "El test de razonabilidad sigue precisos pasos que le imprimen objetividad al análisis de constitucionalidad. Las jurispru- dencias nacional, comparada e internacional desarrollan generalmente el test en tres pasos:

71 Sapag, Mariano, "El principio de proporcionalidad ..., 163-164.

${ }^{72}$ Cianciardo, Juan, El principio de razonabilidad. Del debido proceso sustantivo almodernojuicio de proporcionalidad, 31 y 32 . 
1. El análisis del fin buscado por la medida, 2. el análisis del medio empleado y

3. El análisis de la relación entre el medio y el fin..."

Según lo indicado por el Prof. Risso Ferrand:

A) Las leyes que limitan, restringen o simplemente reglamentan derechos hu- manos deben ser "razonables" por oposición a arbitrarias. Esto deriva de la propia noción de Estado de Derecho sin dificultad alguna y no se requiere de previsiones expresas de interdicción de la arbitrariedad como ocurre en la Constitución española. Las leyes no pueden responder a caprichos sino que deben tener una finalidad y ésta debe ser razonable, racional. Debe procurar los fines explícita o implícitamente definidos por la Constitución y el Derecho Internacional de los Derechos Humanos. Una ley arbitraria, caprichosa, que no responda a ningún propósito o cuyo fin sea contrario a las normas superio- res o simplemente resulte manifiestamente injusta, no puede ser considerada ajustada a la Constitución y deberá ser declarada inconstitucional por violar o exceder el parámetro de la razonabilidad.

B) Además, para quienes separen las nociones de razonabilidad y proporcionali- dad, la ley, además de razonable, deberá cumplir con el principio de propor- cionalidad. En cambio, quienes analicen ambos principios en forma conjunta, concluirán que una ley que no cumple con los parámetros de proporcionalidad no puede ser razonable o, a la inversa, que no puede cumplir con la máxima de proporcionalidad una ley no razonable. 
C) Sin perjuicio de la opción que se prefiera es evidente que, además de lo men- cionado en el precedente literal "A", la ley deberá ser evaluada en cuanto a su proporcionalidad en la restricción o afectación de uno o varios derechos, lo que implica el estudio de (a) su idoneidad para logar el fin perseguido; (b) la necesidad de la restricción (sólo puede admitirse la limitación cuando no haya otro camino para cumplir con el fin o no haya una forma menos gravosa para el derecho intervenido); y (c) que cumpla con la ponderación en sentido estricto.

D) En el marco de un Estado de Derecho respetuoso de los derechos humanos, no puede admitirse la regularidad jurídica de ningún acto que no cumpla con un juicio de razonabilidad y de proporcionalidad en los términos indica- dos. No hay lugar ni puede ser admitido en un Estado de Derecho el actuar 

fuera o contra el Derecho y no puede admitirse el actuar irrazonable ni el desproporcionado ${ }^{73}$.

\section{INTERPRETACIÓN NORMATIVA}

Es imprescindible avanzar en la consideración de las pautas de interpretación que se establecen para las normas vinculadas con derechos humanos, las que puede indicarse verifican una precisión considerable. En este sentido, se incluyen en éstas tres principios centrales que son el principio pro hómine ${ }^{74}$, el principio pro víctima ${ }^{75} \mathrm{y}$ el principio pro libertatis ${ }^{76}$. $\mathrm{Y}$ a partir de esto, es posible afirmar la existencia de una serie de importantes basamentos a la hora de la interpretación de las diferentes disposiciones normativas en la materia, sin perjuicio que los principios señalados no obstan a la aplicación del sistema de derechos humanos y la correspon- diente interpretación compete al jurista a los efectos de realizar una compatibilización acorde con la pretensión última de permitir la convivencia de los diferentes valores jurídicos en juego.

\section{A) LA DIRECTRIZ DE PREFERENCIA DE NORMAS}

Ésta implica que en caso de existir diferente normatividad será necesario optar por la que resulte más favorable al derecho, independientemente de la jerarquía a que responda. Los principios considerados, sin embargo, no van a implicar modificaciones al sistema de derechos humanos y será el jurista quien debe realizar la interpretación compuesta por la correspondiente armonización, en la que se efectúe el 
imprescindible equilibrio de valores, a los efectos de obtener la obligatoria compatibilidad y facilitar la convivencia de los diferentes derechos entre sí, o con las necesidades del bien común.

La directriz de preferencia

Implica que frente a la existencia de distintas opciones de interpretación de una nor- matividad, será imprescindible optar por aquélla que sea más protectora para la persona. En

${ }^{73}$ Risso Ferrand, Martín, Algunas garantías básicas de los derechos humanos (Fundación de Cultura Universitaria, Montevideo, 2008), 125.

74 Principio pro persona.

75 Principio de protección a la víctima.

76 Principio de libertad. 
este sentido es que se hace necesaria la consideración del principio pro libertatis por el que se considera que lo fundamental es la interpretación de la disposición normativa de forma tal que lo más beneficiado sea precisamente la libertad en cuestión. Asimismo debe consi- derarse el significado del principio pro hómine, en la medida que la Corte Interamericana de Derechos Humanos determina que implicará, por un lado, una interpretación por extensión de los derechos humanos y por otro lado, que las limitaciones deberán ser interpretadas en forma estricta.

Todas las normas sobre derechos humanos contenidas en nuestro ordenamiento jurídico deben ser interpretadas armónicamente con las respectivas fuentes normativas convencionales que son internacionales y, a la vez, derecho interno, ya que se han incorporado tales derechos por man- dato del constituyente originario a nuestro orden jurídico, constituyendo límites a la soberanía, vale decir, al poder constituyente instituido o derivado y a todos los órganos y autoridades estatales ${ }^{77}$.

Los derechos humanos siempre tienen fuerza interpretativa expansiva, ya que como indica el Prof. Fernández Segado, el derecho siempre debe interpretarse del modo más am- plio posible, partiendo además de la necesidad de interpretación más beneficiosa para maxi- mizar el contenido del derecho. Por lo mismo, las excepciones deberán interpretarse en forma absolutamente estricta, siendo por tanto inválidas, aquellas interpretaciones que pu- dieren ser de índole analógica o a contrario sensu de una norma que establece precisamente una excepción a una disposición normativa de derechos humanos. 


\section{LEY DE PONDERACIÓN}

La mayoría de la doctrina, cuando se refiere a colisión entre derechos fundamentales en realidad remite a tensiones entre los principios jurídicos que insuflan a tales derechos. Este punto de partida permite superar la postura del juez como mero aplicador de reglas de derecho preconcebidas y obligatorias, abriendo paso a la de intérprete e integrador de un derecho incompleto, compuesto no solamente por normas. Es la tesis de Dworkin, para quien certeramente, al canjearse reglas por principios, se sustituye la disyuntiva de su apli- cación obligatoria, por la de medida en que debe aplicarlos. En definitiva, y como en tantos

${ }^{77}$ Nogueira Alcalá, Humberto, Dogmática de los derechos esenciales. Disponible en: http://www.bibliojuridica.org/ libros/3/1094/16.pdf, (verificado el día 23/05/2015). 
otros planos de la labor judicial, se ingresa aquí a la labor creadora de derecho que también cumplen los jueces.

Hay autores que han acuñado la noción de contenido esencial como aquellos elemen- tos que definen el sentido, alcance y condiciones de ejercicio de los derechos fundamentales (Pérez Luño), y que por fuerza de su cometido hacen que las restricciones o limitaciones, constitucionales y legales, de los derechos fundamentales, no adquieran mesura excesiva, ya que si así ocurriese desnaturalizarían y vaciarían de contenido al derecho fundamental en juego (Alexy). Por tanto, atrás de esta noción se pone de relieve un núcleo inaccesible a las limitaciones a los derechos fundamentales (Rodríguez Calero), lo que de todas maneras no implica que - fuera de dicho núcleo quepan limitaciones indiscriminadas (López Piña)"78. Para ello, será imprescindible efectuar una ponderación de derechos a los efectos de concluir sobre el punto. "Los derechos humanos requieren de la ponderación ${ }^{179}$.

La ponderación implica una forma de aplicación de los principios, que en puridad significan normas que tienen estructura de mandatos de optimización, lo que al decir de Alexy ordena que algo sea realizado en la mayor medida posible, dentro de las posibilidades jurídicas y reales existentes"80. La ponderación se efectúa siguiendo tres pasos: "En el primer paso es preciso definir el grado de la no satisfacción o de afectación de uno de los principios. Luego, en un segundo paso, se define la importancia de la satisfacción del principio que juega en sentido contrario. Finalmente, en un tercer paso, debe definirse si la importancia de la satisfacción del principio contrario justifica la afectación del otro"81.

En mérito a lo establecido esta ponderación será necesaria de ser efectuada frente a la existencia de colisión de principios, la que se produce 
cuando frente a un caso concreto serán relevantes dos disposiciones jurídicas que en principio serían incompatibles. Esta pre- cisamente será utilizada para ubicar una solución a esta incompatibilidad.

La ponderación es racional tanto desde el punto de vista teórico, como desde el pun- to de vista práctico. La ponderación es racional desde el punto de vista teórico, porque se propone como una estructura determinada, clara y

libre de contracción para la aplicación de los derechos fundamentales. Esta estructura resulta de la combinación de la ley de coli-

${ }^{78}$ Bauzá, Marcelo, "Criterios para armonizar la protección de datos personales y el acceso a la información pública”, en Anuario de Derecho Informático № X (2010) Montevideo, 84.

${ }^{79}$ Alexy, Robert, Los derechos fundamentales y el principio de proporcionalidad, pág. 15. Consultable en: http:// www.osconstitucionalistas.com.br/wp-content/uploads/Roberto-Alexy-Los-derechosfundamentales-y-el-principio-de- proporcionalidad.pdf (Verificado el día 23/05/2015).

80 Alexy, Robert, "Epílogo a la Teoría de los derechos fundamentales", en Revista Española de Derecho Constitucional, 66 (2002), Madrid, 86 y 87.

${ }^{81}$ Durán Martínez, Augusto, Derecho a la protección de datos personales y acceso a la información pública (Editorial Amalio Fernández, Montevideo, 2008), págs. 93 y 94, citando a Alexy, Robert en Teoría de los Derechos Fundamentales y a Risso Ferrand, Martín, en Algunas garantías básicas de los derechos humanos. 
sión ${ }^{82}$, la ley de ponderación, la fórmula del $\operatorname{peso}^{83}$ y la carga de la argumentación a favor del Legislador que ella establece. La ponderación es también racional desde el punto de vista práctico, porque su estructura argumentativa satisface las exigencias de la racionalidad del discurso jurídico y como consecuencia permite fundamentar correctamente sus resultados normativos en el marco del sistema jurídico ${ }^{84}$.

Es posible que los principios que colisionan se encuentren en situación de igual je- rarquía considerando la fuente normativa que los contiene, sin embargo, uno de éstos podrá prevalecer en función de la consideración de la predominancia valorativa societaria en un momento dado. También es importante que la ponderación facilite un cierto margen de acción a quien debe efectuar la interpretación sobre todo en relación con la elección de la preponderancia frente a la afectación de los principios. Ahora bien, el subjetivismo estará presente, al igual que las valoraciones que efectúen los jueces y éstas a su vez, constituirán un elemento de sustancia para la fundamentación de las diferentes decisiones a adoptar. Si bien la ponderación implica racionalidad aplicativa, esto no significa que se evitará la subjetividad en la determinación que se asumirá por parte del juez.

Finalmente, es preciso enfatizar que la ponderación es un tipo racional de pensa- miento bien conocido y utilizado en diversas áreas de la reflexión humana, que no conduce a una jurisprudencia ad hoc. Incluso los escépticos de la ponderación llevan a cabo una ponderación cuando afirman que la ponderación solo satisface levemente las condiciones de racionalidad en la aplicación de los derechos fundamentales y que, por tanto, debe preferirse otros métodos más racionales, Un juicio como éste implica hacer una ponderación entre los métodos para la aplicación de los derechos 
fundamentales. La manera de eliminar la ponde- ración, consiste en reemplazar su nombre por uno distinto o camuflar su existencia en medio de otra estructura argumentativa ${ }^{85}$. hu-

Para citar este artículo: Laura Nahabetián Brunet, "Normas de derechos

manos: Colisión y complementariedad", Revista de Derecho-UCU, 13 (julio

2016), pp.65-110

82 Bernal Pulido, Carlos, "Los derechos fundamentales y la teoría de los principios. ¿Es la teoría de los principios la base para una teoría adecuada de los derechos fundamentales de la Constitución Española?" Doxa, Cuadernos de Filosofía del Derecho (2007) Alicante, 287.

83 Bernal Pulido, Carlos, “Los derechos fundamentales y la teoría de los principios..., 285.

84 Bernal Pulido, Carlos, "Los derechos fundamentales y la teoría de los principios..., 284.

85 Bernal Pulido, Carlos, "Los derechos fundamentales y la teoría de los principios. ¿Es la teoría de los principios la base para una teoría adecuada de los derechos fundamentales de la Constitución Española?", pág. 287. 


\section{BIBLIOGRAFÍA}

Alexy, Robert, "Derechos Fundamentales y Estado Constitucional Democrático", en $A A V V$

Neoconstitucionalismo, Trotta, Madrid, 2003.

Alexy, Robert, "Epílogo a la Teoría de los Derechos Fundamentales, en Revista Española de Derecho Constitucional, Núm 66, Madrid, 2002.

Alexy, Robert, Los derechos fundamentales y el principio de proporcionalidad. Consultable en: http:// www.osconstitucionalistas.com.br/wp-content/uploads/RobertoAlexy-Los-derechos- fundamentales-y-el-principio-de-proporcionalidad.pdf (Verificado el día 23/05/2015).

Alexy, Robert, Teoría de los derechos fundamentales, Centro de Estudios Políticos y Constitucionales, Madrid, 2007.

Álvarez Conde, Enrique, El régimen político español, Editorial TECNOS, Segunda Edición, Madrid, 1985.

Arango, Rodolfo, El concepto de derechos sociales fundamentales, Legis,

Bogotá, 2005. Atienza, Manuel y Ruiz Manero, Juan, Las piezas del Derecho. Teoría de los enunciados jurídi-

cos, Editorial Ariel, Barcelona, 2007.

Ballarín Javier, "Derechos fundamentales y relaciones entre particulares. La

Drittwirkung en la jurisprudencia del Tribunal Constitucional", en Revista Española de Derecho Constitucional, CEPC № 24, Madrid, 1988.

Bauzá, Marcelo, "Criterios para armonizar la protección de datos personales y el acceso a la información pública", en Anuario de Derecho Informático $\mathrm{N}^{\circ} \mathrm{X}$. Montevideo, 2010. 
Bernal Pulido, Carlos. "Los derechos fundamentales y la teoría de los principios. ¿Es la teoría de los principios la base adecuada de los derechos fundamentales de la constitución española? ", DOXA $\mathrm{N}^{\circ} 30$, Alicante, 2007.

Bilbao Ubillos, Juan, La eficacia de los derechos fundamentales entre particulares, Centro de Estudios Constitucionales, Madrid, 1997.

Bobbio, Norberto, El tiempo de los derechos, Editorial Sistema, Madrid, 1991.

Brown, Wendy, "Lo que se pierden con los derechos", en $A A V V$ La crítica de los derechos, Siglo del Hombre Editores, Bogotá, 2003.

Cárdenas Gracia, Jaime, La argumentación como derecho, Instituto de Investigaciones Jurídicas, UNAM, México, 2005. 
Castillo Córdova, Luis, “¿Existen los llamados conflictos entre derechos fundamentales? Cuestiones Constitucionales", en Revista mexicana de Derecho Constitucional, Instituto de Investigaciones Jurídicas, UNAM, núm 12, enero -junio 2005. México, 2005.

Cea Egaña, Luis, El sistema Constitucional de chile. Síntesis crítica, Facultad de Ciencias Jurídicas y Sociales de la Universidad Austral de Chile, Valdivia, 1999.

Cianciardo, Juan, El principio de razonabilidad. Del debido proceso sustantivo al moder- no juicio de proporcionalidad, Editorial Abaco de Rodolfo Depalma, Buenos Aires, 2004.

Comanducci, Paolo, "Formas de neoconstitucionalismo: un análisis metateórico", en $A A V V$

Neoconstitucionalismo, Trotta, Madrid, 2003.

Comanducci, Paolo, "Problemas de compatibilidad entre derechos fundamentales", en Garantismo. Estudios sobre el pensamiento jurídico de Luigi Ferrajoli, Primera Edición, Editorial Trotta - Instituto de Investigaciones Jurídicas, UNAM, Madrid, 2005.

De Otto y Pardo, Ignacio, "La regulación del ejercicio de los derechos fundamentales. La garantía de su contenido esencial en el artículo 53.1 de la Constitución", en Lorenzo Martín Retortillo e Ignacio de Otto y Pardo, Derechos Fundamentales y Constitución, Civitas, Madrid.

Durán Martínez, Augusto, Derecho a la protección de datos personales y acceso a la infor- mación pública, Editorial Amalio Fernández, Montevideo, 2008.

Estrada, Alexei, "Los Tribunales Constitucionales y la eficacia entre particulares de los de- rechos fundamentales", en $A A V V$ Teoría del 
neoconstitucionalismo, Trotta, Madrid, 2007.

Fernández Farrerez, Germán, El recurso de amparo según la jurisprudencia constitucional.

Comentarios al Título II de la LOCT, Marcial Pons, Madrid, 1994.

Ferrajoli, Luigi, “Juspositivismo crítico y democracia constitucional”, en Isonomía №16, ITAM, México, 2002.

Ferrer i Riba, Josep, Asociaciones, derechos fundamentales y autonomía privada, Civitas, Madrid, 1997.

García Enterría, Eduardo, "La Constitución como norma jurídica”, en AAVV La Constitución española de 1978. Estudio sistemático, Civitas, Madrid, 1981.

Gavara de Cara, Juan, Derechos fundamentales y desarrollo legislativo. La garantía del contenido esencial de los derechos fundamentales en la Ley Fundamental de Bonn, Centro de Estudios Constitucionales, Madrid, 1994.

Grimm, Dieter, Constitucionalismo y derechos fundamentales, Trotta, Madrid, 2006. 
Guastini, Riccardo, "La constitucionalización del ordenamiento jurídico: el caso italiano", en $A A V V$ Neoconstitucionalismo, Trotta, Madrid, 2003.

Loewestein, Karl, Teoría de la Constitución, Ariel Derecho, Barcelona, 1976.

López Medina, Diego, Teoría impura del derecho, Legis, Bogotá, 2004.

Martínez Pujalte, Antonio, La garantía del contenido esencial de los derechos fundamentales, Centro de Estudios Constitucionales, Madrid, 1997.

Mijanjos y González, Javier, Los derechos fundamentales entre particulares, Porrúa, México, 2007. Naranjo de la Cruz, Rafael, Los límites de los derechos fundamentales en las relaciones entrepar-ticulares: la buena fe, Centro de Estudios Políticos y Constitucionales, Madrid, 2000.

Nogueira Alcalá, Humberto, "Aspectos de una teoría de los derechos fundamentales: la deli- mitación, regulación, garantías y limitaciones de los derechos fundamentales" en Ius et Praxis Volumen $11 \mathrm{~N}^{\circ} 2$, Talca, 2005.

Nogueira Alcalá, Humberto, Dogmática de los derechos esenciales. Disponible en: http://www. bibliojuridica.org/libros/3/1094/16.pdf (Verificación el día 23/05/2015).

Peces Barba, Gregorio, Curso de Derechos Fundamentales, Universidad Carlos III de Madrid, 1999.

Peña, Carlos, Sistema Jurídico y Derechos Humanos, Universidad Diego Portales, Santiago, 1996.

Pérez Luño, Antonio, Los derechos fundamentales, Tecnos, Madrid, 1998.

Prats, Eduardo, Derecho Constitucional, Tomo II, Segunda Edición, Editora Impresos Amigo del Hogar, Santo Domingo, 2012.

Prieto Sanchís, Luis, "Constitucionalismo y garantismo", en AAVV Garantismo, Estudios en homenaje a Ferrajoli, Trotta, Madrid, 2005. 
Prieto Sanchís, Luis, "El constitucionalismo de los derechos", en AAVVTeoría del neocons- titucionalismo, Carbonell (ed.), Trotta, Madrid, 2007.

Prieto Sanchís, Luis, Apuntes de Teoría del Derecho, Primera Edición, Editorial Trotta, Madrid, 2005.

Prieto Sanchís, Luis, Estudios sobre Derechos Fundamentales, Editorial Debate, Madrid, 1990. Prieto Sanchís, Luis, Justicia Constitucional y Derechos Fundamentales, Primera Edición.

Editorial Trotta, Madrid, 2003.

Risso Ferrand, Martín, Algunas garantías básicas de los derechos humanos, Fundación de Cultura Universitaria, Primera Edición, Montevideo, 2008.

Risso Ferrand, Martín, Algunas garantías básicas de los derechos fundamentales, Fundación de Cultura Universitaria, Segunda Edición, Montevideo, 2011. 
Rivero, Juan, "Derechos fundamentales y contrato de trabajo: eficacia horizontal y con- trol constitucional", en $A A V V$ El trabajo y la Constitución, Ministerio de Trabajo y Asuntos Sociales, Madrid, 2003.

Rubio Llorente, Francisco, "La Constitución como fuente de Derecho", en $A A V V$ Constitución española y fuentes del Derecho", Vol. I, Instituto de Estudios Fiscales, Madrid, 1979.

Ruiz-Tagle, Pablo, "Una dogmática general para los derechos fundamentales en Chile", en

Revista de Derecho Público, Volumen 63, Santiago de Chile, 2001.

Sapag, Mariano, "El principio de proporcionalidad como límite constitucional al poder del Estado: un estudio comparado", en Dikaion, Año 22 Núm 17, Bogotá, 2008.

Sastre, Santiago, "La ciencia jurídica ante el neoconstitucionalismo", en $A A V V$

Neoconstitucionalismo. Trotta. Madrid, 2003.

Schware, Jürge, Cincuenta años de jurisprudencia del Tribunal Constitucional Federal alemán, Fundación Konrad Adenauer, Ediciones Jurídicas Gustavo Ibañez, Bogotá, 2003.

Tribunal Constitucional de la República de Chile, Sentencia $N^{\circ} 43 / 1987$, de 24 de febrero de 1987.

Tribunal Constitucional de la República de Colombia, Sentencia C033/1993, de 8 de fe- brero de 1993.

Tribunal Constitucional del Reino de España, Sentencia STC N 11/1981, de 8 de abril de 1981. Tribunal Constitucional del Reino de España, Sentencia STC $\mathrm{N}^{\circ} 159 / 1986$, de 12 de diciembre de 1986. 
Tribunal Constitucional del Reino de España, Sentencia STC N 177/1998, de 10 de octu- bre de 1998.

Tribunal Constitucional del Reino de España, Sentencia STC N²/1982, de 29 de enero de 1982.

Tribunal Constitucional del Reino de España, Sentencia STC N²92/2000, de 30 de no- viembre de 2000.

Tribunal Constitucional del Reino de España, Sentencia STC № 53/1985, 11 de abril de 1985.

Tribunal Constitucional del Reino de España, Sentencia STC N 66/1995, de 8 de mayo de 1995.

Tribunal Constitucional del Reino de España, Sentencia STC N¹36/1999, de 20 de julio de 1999. 
Tribunal Constitucional del Reino de España, Sentencia STC №157/1996, de 15 de octu- bre de 1996.

Tribunal Constitucional del Reino de España. Sentencia STC N 37/1989, de 2 de marzo de 1989.

Valdés Dal-Ré, Fernando, Los derechosfundamentales de lapersona del trabajador, Informe Congreso Mundial de Derechos del Trabajo, Montevideo, 2003. Venegas, María, Derechos fundamentales y derecho privado, Marcial Pons, Madrid, 2004. Zagrebelsky, Gustavo, El Derecho Dúctil. Ley, derechos, justicia, Sexta Edición, Editorial Trotta, Madrid, 2005.

Zavala Egas, Jorge, Derecho Constitucional, Tomo I, Edino, Guayaquil, 1999. 